\title{
Simulation of aerosol radiative effects over West Africa during DABEX and AMMA SOP-0
}

\author{
Florent Malavelle, ${ }^{1}$ Véronique Pont, ${ }^{1}$ Marc Mallet, ${ }^{1}$ Fabien Solmon, ${ }^{2}$ Ben Johnson, ${ }^{3}$ \\ Jean-François Leon, ${ }^{1}$ and Catherine Liousse ${ }^{1}$ \\ Received 27 July 2010; revised 5 January 2011; accepted 13 January 2011; published 19 April 2011.
}

[1] The regional climate model RegCM3 has been used to assess optical properties and clear-sky direct radiative forcing (DRF) of mineral dust and carbonaceous aerosols over West Africa for the period October 2005 to April 2006. Our results display a significant seasonal variation of the aerosol single scattering albedo (SSA) due to varying contributions from biomass burning (BB) and dust. During December-January, simulated SSA values dropped to around $0.81-0.83$ at $440 \mathrm{~nm}$ and to $0.80-0.85$ at $675 \mathrm{~nm}$ when absorbing aerosols from biomass burning dominate the mixture. During March and April, when mineral dust dominates, simulated SSA values increased reaching around $0.90-0.92$ at $440 \mathrm{~nm}$ and $0.94-0.96$ at $675 \mathrm{~nm}$. The simulated aerosol optical thickness (AOT) was maximum over central Africa where it far exceeded estimates of AOT from satellite which showed the greatest AOT in the gulf of Guinea. This discrepancy was linked to an overestimation of BB emissions in central Africa and a possible underestimation of AOT over central Africa due a high occurrence of cloud and associated difficulties in cloud screening. The DRF calculations were extremely sensitive to aerosol optical properties and underlying surface albedo. Over dark surfaces, the sum of shortwave (SW) and longwave (LW) top of the atmosphere (TOA) direct radiative forcing averaged from December to February was negative $\left(-5.25\right.$ to $\left.-4.0 \mathrm{~W} / \mathrm{m}^{2}\right)$ while over bright surfaces it was close to zero $\left(-0.15 \mathrm{~W} / \mathrm{m}^{2}\right)$. Large differences between SW surface and SW TOA direct radiative forcing indicated that SW absorption had an important influence on the radiative budget. The SW radiative heating rate associated with the aerosol reached $1.2 \mathrm{~K} / \mathrm{d}$ at local noon (diurnal mean of $0.40 \mathrm{~K} / \mathrm{d}$ ) over Niamey $\left(\sim 13.5^{\circ} \mathrm{N}, 2^{\circ} \mathrm{E}\right)$ and peaked at altitudes of $2-4 \mathrm{~km}$, corresponding to the $\mathrm{BB}$ aerosol layer.

Citation: Malavelle, F., V. Pont, M. Mallet, F. Solmon, B. Johnson, J.-F. Leon, and C. Liousse (2011), Simulation of aerosol radiative effects over West Africa during DABEX and AMMA SOP-0, J. Geophys. Res., 116, D08205, doi:10.1029/2010JD014829.

\section{Introduction}

[2] Atmospheric aerosols have a direct effect on climate by scattering and absorbing shortwave (SW) and longwave (LW) radiation [Charlson et al., 1992; Satheesh and Ramanathan, 2000]. Scattering aerosols (e.g., sulphates) increase the amount of backscattered solar radiation to space leading to a loss of energy for the "surface-atmosphere" system while on the other hand, absorbing particles (black and brown carbon, certain mineral dust) increase the energy that is kept in the "surface-atmosphere" system. Important uncertainties in terms of the net aerosol Direct Radiative Forcing (DRF) on Earth's climate still remain [Forster et al., 2007] despite better assessment of emissions, improvements in remote

\footnotetext{
${ }^{1}$ Laboratoire d'Aérologie, UMR5560, Université Paul Sabatier, CNRS Toulouse, France.

${ }^{2}$ International Centre for Theoretical Physics, Trieste, Italy.

${ }^{3}$ Met Office, Exeter, UK.
}

Copyright 2011 by the American Geophysical Union. 0148-0227/11/2010JD014829 sensing satellite observations, dedicated field campaigns and aerosols surface networks which offer better constraints for numerical models. For instance, the global DRF due to anthropogenic aerosols is estimated as $-0.5( \pm 0.4) \mathrm{W} / \mathrm{m}^{2}$ [Forster et al., 2007] (i.e., a cooling effect at top of the atmosphere during daytime). This forcing (and even the associated uncertainty) is of a comparable order of magnitude to the radiative forcing from anthropogenic greenhouse gases, and is likely to partially offset their global warming [Andreae et al., 2005]. However, the top of the atmosphere (TOA) DRF of aerosols varies strongly both spatially and temporally. Indeed, unlike greenhouse gases, aerosols show a large variability in their spatial distribution due to shorter lifetime. Their physical-chemical-optical properties also vary greatly depending on emissions sources and aging (i.e., physical and chemical changes via mixing and other processes) during transport. The magnitude, and even the sign, of the TOA DRF varies among different regions and is controlled by several factors including aerosol absorption capacity, the surface reflectivity, and the reflectivity of the underlying 
cloud and/or aerosol layers [Russell et al., 2002; Haywood et al., 2003; Johnson et al., 2008b].

[3] Africa is the world's largest source of biomass burning (BB) aerosols and mineral dust [Prospero et al., 2002; van der Werf et al., 2006]. The region is influenced by large amounts of mineral dust aerosols that result from wind erosion of soils in the arid northern parts of the continent. These mineral dust particles are emitted continuously during the year and are able to modulate the radiative balance both at local [Slingo et al., 2009] and regional scales [Grini et al., 2006; Solmon et al., 2008; Milton et al., 2008, Mallet et al., 2009; Cavazos et al., 2009] especially during intense events of dust uplift that regularly occur [e.g., Myhre et al., 2003; Slingo et al., 2006; Heinold et al., 2007; Tulet et al., 2008; Crumeyrolle et al., 2010]. Several studies have already investigated the response of the West African climate to the DRF of dust aerosols. Although no clear consensus on the net effect of dust aerosols on West African climate has been achieved, it is clear that the dust DRF has an impact on the hydrological cycle. Links with the development and dynamics of the West African monsoon are suggested in several recent studies [e.g., Solmon et al., 2008; Konaré et al., 2008; Yoshioka et al., 2007; Miller et al., 2004; Peyrillé et al., 2007; Lau et al., 2009; Klüser and HolzerPopp, 2010; Perlwitz and Miller, 2010].

[4] The West African atmosphere is also heavily loaded by carbonaceous aerosols resulting from the incomplete combustion of fossil fuels, biofuels (domestic fire) and biomass burning [Liousse et al., 1996; Cooke et al., 1999; Junker and Liousse, 2008]. These carbonaceous aerosols, which mostly result from anthropogenic activities over the region, are able to absorb significantly amount of solar radiation due to their sizes and the high content of black carbon (BC). Biomass burning emissions are likely to be the dominant contributor among these sources of carbonaceous aerosols in the region [Liousse et al., 2004; Myhre et al., 2008]. These follow a well marked seasonal cycle of burning activity peaking in December/January during the dry period (approximately from November to May). Remote sensing observations of the fine mode aerosol optical thickness (AOT) show that biomass burning aerosols are a major contributor to the total bulk AOT in West Africa during that period [Tanré et al., 2001].

[5] Within the framework of the recent AMMA (African Multidisciplinary Monsoon analysis) SOP-0 and DABEX (Dust and Biomass Burning Experiment) [Haywood et al., 2008] field campaigns; several studies [Derimian et al., 2008a; Johnson et al., 2008a; Mallet et al., 2008; Milton et al., 2008; Raut and Chazette, 2008, McFarlane et al., 2009] have investigated the role of smoke particles on the local radiative budget. Johnson et al. [2008a] reported a single-column DRF of $-1.2,-10.7$ and $9.5 \mathrm{~W} \mathrm{~m}^{-2}$ at the top of the atmosphere (TOA), surface and into the atmospheric layer, respectively. Milton et al. [2008] show that, at Niamey during AMMA SOP0/DABEX, approximately $50 \%$ of the reduction of surface solar insolation is due to biomass burning and $50 \%$ is due to mineral dust, with the contribution of dust increasing as the biomass burning activity decreases. In many studies, a large difference between surface and TOA DRF ratio is reported, from which a high degree of solar absorption can be inferred; and this absorption has been attributed to biomass burning particles. In addition to those single-column studies, two works [Myhre et al., 2008; Johnson et al., 2008a] address the direct radiative impact of smoke and dust aerosols at the regional scale over West Africa. First, Myhre et al. [2008] used the OSLO chemical transport model to estimate clear and full sky TOA radiative effect of biomass burning during January-February 2006. Second, Johnson et al. [2008a] performed 3 years of simulations using the HadGEM2-A general circulation model to calculate clear-sky TOA direct forcing. Both studies found the TOA DRF of mixed dust and biomass burning aerosols to be positive over the more northern regions of high surface reflectivity $\left(\sim 15^{\circ} \mathrm{N}\right.$ northward) but negative over ocean and darker regions. Both studies also found that the underlying layer of scattering aerosols (dust) amplified the absorption by elevated biomass burning aerosol leading to small but not insignificant increases in the TOA forcing. Another common finding was a large overestimation of AOT over central Africa and an underestimation of AOT over the gulf of Guinea when compared to satellite AOT retrievals. These differences were linked to the higher fuel load in the inventories as estimated in the GFED [van der Werf et al., 2006] biomass burning inventories.

[6] The main goal of this work is to assess the direct radiative forcing of mixed aerosols. The ICTP's RegCM3 regional climate model version 3 (RegCM3) has been used to perform simulations for the dry season 2006 with new burning biomass inventories that were developed in the framework of the AMMA campaign [Liousse et al., 2010], and the modeled results have been compared with observational data obtained during the AMMA-SOP0/DABEX experiment. The present study focuses on the optical properties of anthropogenic smoke particles (e.g., aerosol optical thickness, AOT and single scattering albedo, SSA), the vertical distribution of aerosols (anthropogenic smoke above dusty layer observed during the dry season [Pelon et al., 2008; Heese and Wiegner, 2008; Johnson et al., 2008a; Kim et al., 2009; Léon et al., 2009]) and profiles of SW heating rates due to aerosols. These SW heating rates are particularly important over this region as they could drive Elevated Heat Pump (EHP) feedbacks [Lau et al., 2009; Solmon et al., 2008] which are likely to impact the hydrological cycle over West Africa. For that reason, the aerosol induced SW heating rate needs to be carefully studied before the aerosol climate effect via EHP can be accurately quantified.

[7] The structure of the paper is the following. Section 2 describes the characteristics of the RCM model and the setup for modeling the aerosols. In section 3, the RegCM3 results are compared to a large range of observations including Sun photometer of Aerosol Robotic Network (AERONET) [Holben et al., 1998] (section 3.1.1), satellite observations (section 3.1.2) and LIDAR profiles (section 3.2). The TOA and Surface (SW and LW) direct radiative forcings of aerosols are reported in section 3.3.1, together with a discussion on the sensitivity of carbonaceous aerosol absorbing properties (section 3.3.2). Finally, the RegCM3 simulated aerosol SW heating rate is compared to a detailed radiative transfer model 
constrained by DABEX flights measurements (section 3.4). Results and perspectives are summarized in section 4 .

\section{Simulation of the 2006 Dry Season}

\subsection{Model Description}

[8] Here, we used the RegCM3 model developed at the Abdus Salam International Centre of Theoretical Physics (ICTP) [Giorgi and Mearns, 1999; Pal et al., 2007]. As mentioned previously, our aim is to assess the direct radiative forcing of mixed dust and carbonaceous aerosols, the primary compounds observed in the West African atmosphere during the dry season. We simulated the period from November 2005 to April 2006 (plus 1 month spin-up period) which covered the transition in aerosol mixture between "dust + carbonaceous" aerosols and "pure dust" aerosols cases. This particular year was chosen because of the data available from the AMMA SOP-0/DABEX campaign [Haywood et al., 2008] that help us to constrain and evaluate the aerosol parameterization in RegCM3, especially concerning BB particles. The following step of this work will be to study the climatic impact of mixed aerosols for a long time period and to describe the intraseasonal variability. The model is run over the West African region, on 23 hydrostatic sigma levels in the vertical, and at $45 \mathrm{~km}$ horizontal resolution. The NCEP2 reanalysis [Kanamitsu et al., 2002] is used as boundary forcing. RegCM3 uses the radiative package of the NCAR Community Climate Model 3 (CCM3) [Kiehl et al., 1998]. Its predecessor (CCM2) accounted for the effects of $\mathrm{H}_{2} \mathrm{O}, \mathrm{O}_{3}, \mathrm{O}_{2}, \mathrm{CO}_{2}$. The CCM3 is structured in the same way, but it includes new features such as the effect of additional greenhouse gases $\left(\mathrm{NO}_{2}, \mathrm{CH}_{4}, \mathrm{CFCs}\right)$, atmospheric aerosols, and cloud ice. The solar radiation scheme of the RegCM3 employs the delta-Eddington approximation for radiative flux calculations, and the wavelength spectrum is divided into 18 discrete intervals from 0.2 to $4.5 \mu \mathrm{m}$ [Briegleb, 1992; Kiehl et al., 1996]. Seven of these span the ultraviolet (0.2 to $0.35 \mu \mathrm{m})$, one covers the visible $(0.35$ to $0.7 \mu \mathrm{m})$ while the remaining bands cover the infrared or special absorption windows. The radiative transfer calculations are fully coupled with an aerosol scheme [Solmon et al., 2006] to perform simulations including aerosol radiative effects in order to study feedbacks on atmospheric dynamics. The convective scheme used here is the Grell scheme [Grell, 1993]. The scheme for land surface is based on the Biosphere-Atmosphere Transfer Scheme (BATS) [Dickinson et al., 1993] and is employed to compute surface net solar radiation, sensible and latent heat fluxes, momentum fluxes, and surface temperature from prescribed vegetation and soil types. In RegCM3, additional modifications have been made to BATS in order to account for the subgrid variability of topography and land cover using a mosaic-type approach (named SUBBATS) [Giorgi et al., 2003]. The Planet Boundary Layer scheme developed by Holtslag et al. [1990] is based on a nonlocal diffusion concept that takes into account counter-gradient fluxes resulting from large-scale eddies in an unstable, well-mixed atmosphere.

[9] Aerosols are described by a single moment scheme that predicts the mass concentration of aerosol tracers but the evolution of the size distribution for each tracer cannot be explicitly simulated. The diagnosed concentration fol- lows the tracer equation determined by Qian et al. [2001] and Solmon et al. [2006]. In this equation the different terms represent advection, horizontal and vertical turbulent diffusion, convective transport (in convective clouds, aerosols are vertically redistributed), wet removal by large-scale and convective rain, dry deposition, surface emissions and production and losses due to physicochemical transformations. This last point only applies to sulphate chemistry (gaseous $\mathrm{SO}_{2}$ to particulate $\mathrm{SO}_{4}^{2-}$ ). Finally, no aerosol-cloud interactions are considered (the indirect aerosol effects) by the RegCM3 model. All other assumptions regarding aerosol optical properties and sources are discussed where necessary.

\subsection{Aerosol Modeling Setup and Assumptions}

[10] Recent developments in RegCM3 have been achieved in order to simulate anthropogenic aerosols [Solmon et al., 2006] and mineral dust aerosols [Zakey et al., 2006; Solmon et al., 2008]. Different aerosol species are represented by external mixtures. This representation is in good agreement with recent in situ observations obtained during the AMMA SOP-0 experiment [Haywood et al., 2008] showing clearly two distinct aerosol layers, with BB particles located above mineral dust aerosols.

[11] Key parameters for aerosol radiative effect modeling are the emission (location and amount) that govern the mass of aerosols in the atmosphere and the optical properties that are used as input for the radiative transfer modeling. The concerned optical properties for the SW radiation routines are the mass extinction coefficient $\left(K_{\text {ext }}\right.$, in $\left.\mathrm{m}^{2} \mathrm{~g}^{-1}\right)$, the single scattering albedo (SSA) and the asymmetry parameter $(g)$. In the LW regime, we only consider the direct radiative impact of mineral dust due to their size. It is taken into account through an emissivity/absorptivity scheme detailed by Solmon et al. [2008]. Here, the LW scattering effect is neglected and the only optical property required is the absorption coefficient $\left(Q_{a b s}\right)$, which is set to a constant value of $0.1 \mathrm{~m}^{2} \mathrm{~g}^{-1}$ consistent with Wang et al. [2006].

\subsubsection{Inventories Emissions and Deposition}

[12] In this study, dust aerosols are the only natural particles considered in our simulations (i.e., sea salt or volatile organic compounds are not included). Carbonaceous and sulphate aerosols from biomass burning, biofuel (BF) and fossil fuel (FF) account for the anthropogenic aerosols. All the species are included as passive tracers. The dust aerosols are separated into 4 bins $(0.1-1.0 \mu \mathrm{m} ; 1.0-2.5 \mu \mathrm{m} ; 2.5-5.0 \mu \mathrm{m} ; 5.0$ $20 \mu \mathrm{m}$ in diameter). The associated SW optical properties (reported in Table 1) are similar to those described by Solmon et al. [2008]. Combustion aerosols are in fact a complex mixture of several compounds (black carbon and organic matter along with nitrate, sulphate, ammonium, etc), however because RegCM3 lacks a full aerosol/chemistry module, carbonaceous aerosols are described using two tracer, black carbon $(\mathrm{BC})$ and organic carbon $(\mathrm{OC})$. The sulphate aerosols are represented by two tracers, $\mathrm{SO}_{2}$ (the gaseous aerosol precursor) and the SO4 (the anthropogenic second organic aerosol).

[13] The unique source terms for $\mathrm{BC}, \mathrm{OC}, \mathrm{SO}_{2}$ and DUST tracers are the surface emissions. Dust aerosol emissions are prescribed by an online dynamical scheme [Zakey et al., 2006] which follows the saltation (horizontal flux) and sandblasting (vertical flux) parameterizations from Marticorena and Bergametti [1995] and Alfaro and Gomes 
[2001]. Emissions of carbonaceous and sulphate aerosols are prescribed by inventories. Biomass burning $\mathrm{OC}$ and $\mathrm{BC}$ inventories (bbAMMA hereafter) [Liousse et al. [2010] are based on the Système Probatoire d'Observation de la Terre (SPOT) burnt vegetation areas for the years 2005 and 2006 [Michel et al., 2005; Liousse et al., 2010]. Anthropogenic (FF and $\mathrm{BF}$ ) carbonaceous aerosol emissions estimates are based on the most recently available year (2003) of the Junker and Liousse [2008] inventory. Estimation of the emission of carbonaceous aerosols emissions $(\mathrm{BC}+\mathrm{OC}$ noted BCOC hereafter) shows that for the DJF season (December-February average), biomass burning accounts for almost all the mass of BCOC released. Based on these inventories, total BCOC emissions for the year 2005 over North Africa $\left(5^{\circ} \mathrm{S}-25^{\circ} \mathrm{N}\right.$ and $\left.20^{\circ} \mathrm{W}-30^{\circ} \mathrm{E}\right)$ are $0.66 \mathrm{Tg}$ for the $\mathrm{FF}$ and $\mathrm{BF}$ while it is $5.2 \mathrm{Tg}$ for $\mathrm{BB}$. Biomass burning emissions occur mainly during the dry season whereas FF and $\mathrm{BF}$ emissions are constant throughout the year. Therefore, during the dry season, the contribution of $\mathrm{BB}$ to total aerosol loading is dominant, besides from the contribution from dust. Similar conclusions were reported in a study from Myhre et al. [2008] based on different emission data sets and a different model.

[14] Aerosol sinks processes are represented here by dry and wet deposition. For dust aerosols, addition of a sizedependent particle gravitational settling term and a dry deposition scheme including turbulent transfer in the surface layer and surface interception as a function of land cover characteristic is considered [Zakey et al., 2006]. For the nondust aerosols species, such a parameterization of dry deposition is not included in the RegCM3 model and constant dry deposition velocities are assumed. These values are taken from Cooke et al. [1999] and are equals to $0.2 \mathrm{~cm} \mathrm{~s}^{-1}$ and $0.025 \mathrm{~cm} \mathrm{~s}^{-1}$ over water and land, respectively. $\mathrm{BC}$ and DUST tracers are considered as hydrophobic whereas OC and $\mathrm{SO} 4$ are assumed to be hydrophilic involving different wet deposition rates. Wet deposition is treated following Giorgi [1989] for resolvable-scale precipitation and Giorgi and Chameides [1986] for convective precipitation.

\subsubsection{Aerosol Optical Properties}

[15] In the frame of the AMMA-SOP0/DABEX experiment, Johnson et al. [2008a] reported a SSA value of 0.81 $(550 \mathrm{~nm})$ for BB aerosols from aircraft measurements. This value is particularly low in comparison to other regions where biomass burning also occurs [e.g., Haywood et al., 2003; Dubovik et al., 2002; Reid et al., 2005]. It indicates very strong absorption of solar radiation associated with significant diabatic heating of the atmosphere during the daytime.

[16] In order to represent accurately the aerosol direct radiative effects over West Africa, the optical properties observed during AMMA SOP-0/DABEX have been used to update biomass burning aerosol parameterizations in the RegCM3 model. We recomputed the BC and OC optical properties $\left(K_{\text {ext }}, S S A, g\right)$, in order to refine the parameters that are needed as input for the radiative transfer code. These computations were performed offline by using Mie calculations based on the mass distributions for aged aerosols obtained from Dekati impactor measurements at Djougou during the AMMA-SOP0 [Pont et al., 2009]. The measured parameters of the $\mathrm{BC}$ and $\mathrm{OC}$ lognormal mass size distributions are reported in Table 2. Refractive index, 
Table 2. Parameter of the Lognormal Distribution That Fit the $\mathrm{BC}$ and $\mathrm{OC}$ Mass Distribution Measured at Djougou During AMMA-SOP0

\begin{tabular}{lcccccc}
\hline Compounds & \multicolumn{3}{c}{ OC } & & \multicolumn{3}{c}{$\mathrm{BC}$} & \\
\hline Mode & 1 & 2 & 3 & 1 & 2 & 3 \\
Mass $\left(\mu \mathrm{g} / \mathrm{m}^{3}\right)$ & 0.05 & 0.52 & 0.25 & 0.02 & 0.13 & 0.08 \\
$\mathrm{D}_{\text {geom }}(\mathrm{nm})$ & 40 & 320 & 2000 & 50 & 500 & 5400 \\
Sigma & 2.10 & 1.90 & 1.80 & 2.0 & 2.10 & 2.0 \\
\hline
\end{tabular}

denoted $n$, is also required during the calculations. For $\mathrm{BC}$, a value of $1.95+0.790 \mathrm{i}$ was used [Bond and Bergstrom, 2006]. Because of the lack of data characterizing OC refractive indices, we adjust its imaginary part, which governs the shortwave absorption, in order to obtain a SSA value close to 0.81 (at $550 \mathrm{~nm}$ ) for the external mixture of $\mathrm{BC}$ and $\mathrm{OC}$. Here, a constant $n$ equal to $1.45+0.01 \mathrm{i}$ in the visible spectra was used for $\mathrm{OC}$, which is consistent with recent studies on OC spectral absorption [Kirchstetter et al., 2004; Schkolnik et al., 2007; Dinar et al., 2008; Chakrabarty et al., 2010]. These studies highlight the role of HUmis-LIke Substances (HULIS) that enhance $O C$ absorption particularly in the UV spectrum [Kirchstetter et al., 2004]. It has been shown that HULIS matter is found in abundance in organic compounds resulting from biomass burning [Andreae and Gelencser, 2006].

[17] Finally, the optical properties of all tracers were computed both at the $18 \mathrm{RegCM} 3$ radiative transfer bands and also at the wavelengths at $440 \mathrm{~nm}$ and $675 \mathrm{~nm}$ to allow direct comparisons with integrated AERONET AOT and SSA. Table 1 lists the dry optical properties for the four DUST tracers as well as the $\mathrm{BC}$ and $\mathrm{OC}$ tracers used as input for the RegCM3 simulations.

[18] We have assumed that the optical properties of the tracers are constant in space and time and representative of an aerosol from the regional haze. As mentioned above, carbonaceous aerosols in the simulations are mostly derived from biomass burning sources. There is observational evidence of a rapid aging these aerosols (within just a few hours after the emission) and evidence that the optical properties also rapidly reach an equilibrium state [ $\mathrm{Abel}$ et al., 2003; Johnson et al., 2008b; Hungershoefer et al., 2008]. Thus, considering a constant state for BC and OC appears very reasonable, certainly in terms of first-order estimates of the direct aerosol effect of aerosol on seasonal and regional scales. Nevertheless, we consider the effect of relative humidity on OC optical properties by applying a corrective function to the optical properties according to equation 6 given by Magi and Hobbs [2003].

\subsection{The Biomass Burning Seasonal Cycle}

[19] To compare the intensity of biomass burning emissions for the dry season studied with longer cycles, we represented in Figure 1, the 30 days sliding average of the cumulative $\mathrm{BC}+\mathrm{OC}$ from the bbAMMA inventory over the $5^{\circ} \mathrm{S}-20^{\circ} \mathrm{N}$ and $15^{\circ} \mathrm{W}-30^{\circ} \mathrm{W}$ region from April 2000 to February 2007. Although large-scale climate variability, such as the phase of the El Niño-Southern Oscillation (ENSO) does have some impact on seasonal biomass burning emissions [Anyamba, 2003; van der Werf et al., 2004], emissions peak in the dry season from December to February and thus it is expected that the contribution of BB aerosols to the total bulk aerosols AOT during this period is high. It is important to note that for 2006 biomass burning emissions are lower than in the other years as reported by Derimian et al. [2008a].

\subsection{Comparative Data}

[20] In order to evaluate the spatial distribution of AOT simulated by RegCM3, we have compared modeled AOT to that retrieved from remote sensing instruments onboard different polar orbiting satellites, namely, MODIS (MODerateresolution Imaging Spectroradiometer) on AQUA, MISR (Multiangle Imager SpectroRadiometer) on TERRA, and POLDER (Polarization and Directionality of the Earth's Reflectances) on PARASOL.

[21] The standard MODIS aerosol retrieval algorithm over land uses the dark target approach [Kaufman et al., 1997] and assumes a fixed relation between $0.47,0.64$ and the $2.1 \mu \mathrm{m}$ channels. This is a valid assumption for most vegetated land surfaces except over bright surfaces (e.g., desert regions) and as a result there are substantial data gaps in the standard MODIS aerosol product over land. Here, we use the $0.55 \mu \mathrm{m}$ MODIS/Aqua AOT (daily level-3 data, MYD08 product from collection 5.1), given on a $1^{\circ} \times 1^{\circ}$ grid. Over vegetated land MODIS retrieves AOT in three visible channels with high accuracy of $\pm 0.05 \pm 0.15^{*} \tau$ where $\tau$ is the aerosol optical thickness (and $\pm 0.03 \pm 0.05^{*} \tau$ over ocean) [Levy et al., 2007].

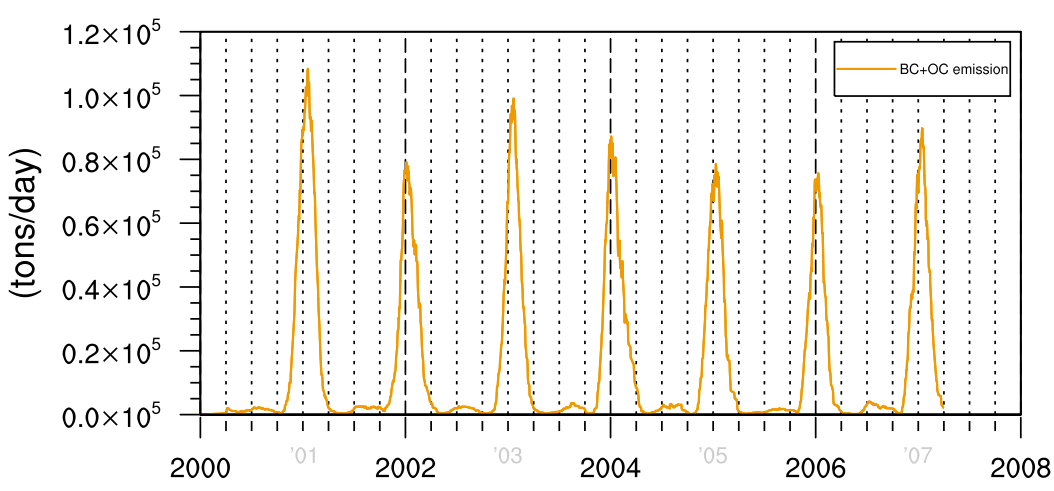

Figure 1. Thirty days sliding averaged over $5^{\circ} \mathrm{S}-20^{\circ} \mathrm{N}$ and $15^{\circ} \mathrm{W}-30^{\circ} \mathrm{E}$ of $\mathrm{BC}+\mathrm{OC}$ emission (in tons/d) from based on bbAMMA biomass burning inventories established from SPOT data. 


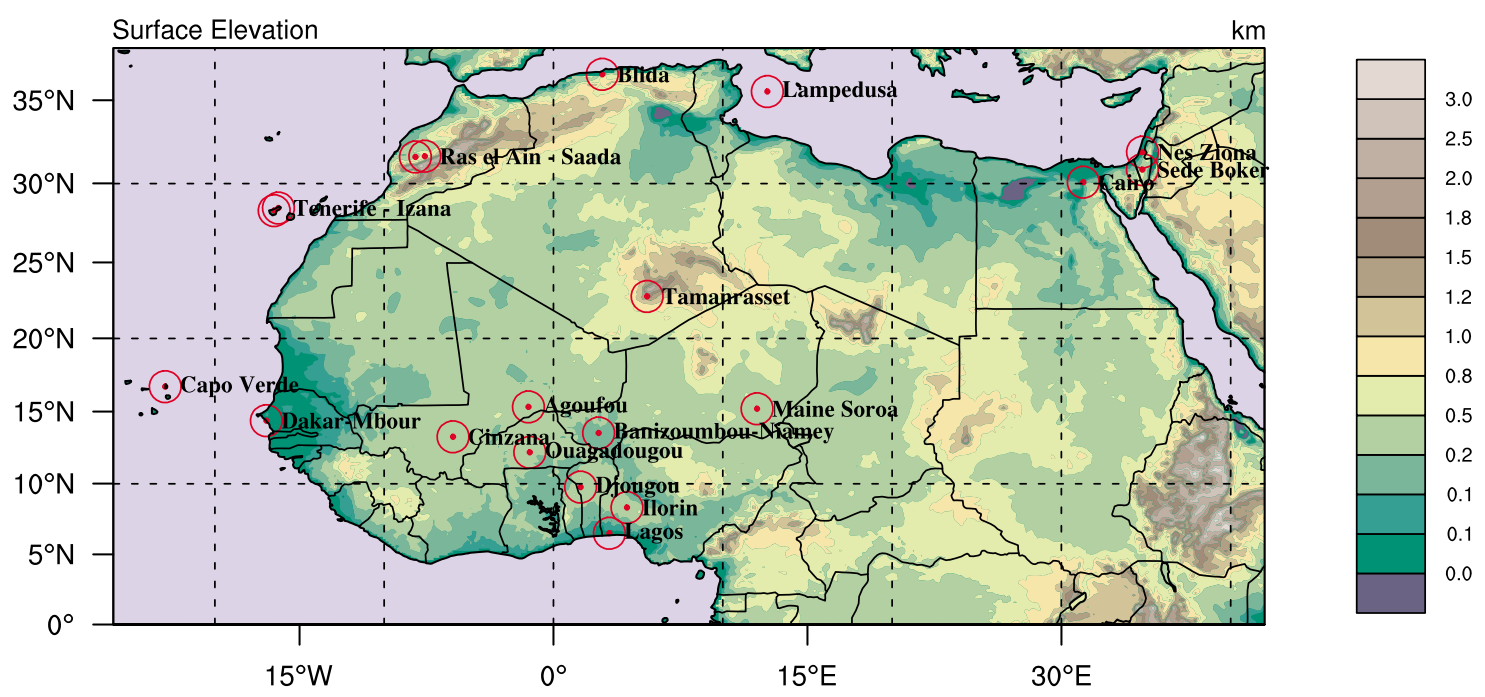

Figure 2. Location of AERONET sites used in this study (Lagos location is also marked although there is no AERONET Sun photometer operating in this city).

[22] MISR provides estimates of AOT using four different wavelength channels and nine different viewing angles. The different geometry views allow MISR to retrieve AOT without any limitations due to surface reflectance [Diner et al., 1998]. However, one week is necessary to fully cover the studied domain due to the narrow swath of the instrument. Here we consider the AOT estimated at $555 \mathrm{~nm}$ (daily level-3 data given on a $0.5^{\circ} \times 0.5^{\circ}$ grid, MISR MIL3DAE products version F15_0031). A global comparison of MISR and AERONET AOT shows that overall, $2 / 3$ of MISR retrieved AOT falls within 0.05 or $20 \%$ of AERONET AOT and about $1 / 3$ is within 0.03 or $10 \%$ [Kahn et al., 2005].

[23] Finally, we consider AOT products (Pr ATM level 3 data given on a $1 / 6^{\circ} \times 1 / 6^{\circ}$ grid) from the POLDER instrument aboard the PARASOL satellite. The sensor is capable of measuring multispectral, multidirectional and polarized radiances. The observed multiangle polarized radiances can be exploited to better separate the atmospheric contribution from the surface contribution over both land and ocean [Deuzé et al., 2001; Herman et al., 2005]. The inversion algorithm allows estimation of the total AOT and discrimination between small spherical particles (accumulation mode) and large spherical or nonspherical particles (coarse mode) over the ocean. A limitation of POLDER is its rather coarse spatial resolution of about $6 \mathrm{~km}$, which affects the ability to account for scene heterogeneities. The fine mode AOT product reflects the aerosol loading of just the fine mode of the aerosol size distribution (particle sizes smaller than about $0.35 \mu \mathrm{m}$ in radius).

[24] We have also compared AOT simulated by RegCM3 to Sun photometer measurements from AERONET sites in the domain (see Figure 2 for the location of these stations). AERONET is a globally distributed network of automated ground-based instruments (CIMEL spectral radiometers) and a data archive system [Holben et al., 1998]. In this study, we based our comparisons of the RegCM3 AOT and SSA time series on the monthly averaged AERONET AOT level 2.0 (cloud-screened and quality-assured data) data and SSA level 2.0 sky radiance inversions, both at 440 and $675 \mathrm{~nm}$. Estimates of the uncertainties for AOT are \pm 0.015 at wavelengths $>440 \mathrm{~nm}$ while uncertainty in terms of SSA is estimated to be \pm 0.03 for AOT $>0.2( \pm 0.07$ for AOT $<$ 0.2) [Dubovik et al., 2000]. The monthly averaged AERONET level 2.0 AOT and SSA are calculated using the daily average for each day. In turn, the daily averaged AERONET level 2.0 AOT and level 2.0 inversions are calculated from all observations for each day when three or more measurements are available. For the level 2.0 SSA the number of available data is much lower than the level 2.0 AOT due to the measurement procedure and more stringent criteria for calculation. The Sun photometer estimates the AOT from the measurement of the direct attenuation of irradiance from the Sun, while the SSA is retrieved using the sky brightness observation in the Almucantar plan. To compute a mean SSA fitted to RCM SSA outputs from these SSA inversions, we have selected AERONET sites that present at least 10 daily means within the month. For certain sites however, these criteria are not met and some monthly means may be somewhat biased compared to reality. These values are compared with the monthly averaged AERONET SSA of the period of interest (November 2005 to April 2006) with the "climatological" monthly averaged AERONET SSA. Values that deviated from the climatology by more than the associated uncertainty $( \pm 0.03)$ were removed from the plot.

[25] In addition, we use estimates of carbon monoxide (CO) concentrations (a good tracer of combustion) provided by the MOPITT instrument onboard the TERRA satellite [Deeter et al., 2003]. Because of the relatively high uncertainty associated with this product, particularly in terms of near-surface estimates, we only used this product to qualitatively identify regions of strong combustion.

[26] Extinction profiles were acquired at Niamey [McFarlane et al., 2009] and Mbour [Léon et al., 2009] using autonomous Micro Pulse LIDAR (MPL) systems working in the visible range (at $523 \mathrm{~nm}$ and $532 \mathrm{~nm}$, 
respectively). The main uncertainties in the MPL derived extinction profiles results from the unknown overlap correction, uncertainty in the AOD used to scale the derived profiles and the unknown LIDAR ratio profile. Assuming that all causes of uncertainties (overlap correction, AOD, constant LIDAR ratio) are independent and in the same direction, the total uncertainty in the derived extinction profiles is estimated to be $27 \%$ in the dusty layer and $39 \%$ in the biomass burning layer (S. McFarlane, personal communication, 2010).

\section{Results and Discussions}

\subsection{Simulated AOT and SSA}

\subsubsection{Comparison With the AERONET Photometer Network}

[27] First, simulated AOT and SSA is compared with AERONET observations. The simulated AOT is obtained by integrating the aerosol extinction over the 23 vertical levels,

$$
A O T=\sum_{i=0}^{n l e v} E X T_{i}^{*} D_{Z_{i}}=\sum_{i=0}^{n l e v} A O T_{i},
$$

where $\mathrm{EXT}_{\mathrm{i}}$ is the extinction of the layer and $\mathrm{Dz}_{\mathrm{i}}$ is the path of the level layer. The SSA of the column, which integrates the mixture of different aerosol types, is computed as follows:

$$
S S A=\frac{\sum_{i=0}^{n l e v} S S A_{i}{ }^{*} A O T_{i}}{\sum_{i=0}^{n l e v} A O T_{i}},
$$

where $\mathrm{SSA}_{\mathrm{i}}$ and $\mathrm{AOT}_{\mathrm{i}}$ are the AOT and the SSA, respectively, at each vertical level of the model.

[28] Figure 3 shows comparisons of the monthly averaged AOT and SSA simulated by RegCM3 with AERONET retrievals for the Sahelian sites of Agoufou, Djougou, Maine Soroa, Banizoumbou, Cinzana, Ilorin and Cape Verde.

\subsubsection{SSA}

[29] SSA retrieved from AERONET inversions drop to the lowest values (around 0.80 at $440 \mathrm{~nm}$ ) in December and January when absorbing aerosols from biomass burning dominate the atmospheric burden. The model simulates this trend accurately even though it tends to slightly overestimate the SSA values compared to AERONET. On average, simulated values remain in the range of estimated uncertainty from the sky radiance inversions. The monthly averaged RegCM3 SSA is about 0.81-0.83 (0.80-0.85) at $440 \mathrm{~nm}(675 \mathrm{~nm})$ for December and January, and is in good agreement with observations from the DABEX campaign [Johnson et al., 2008b].

[30] During the months of March and April, atmospheric aerosol content is dominated by mineral dust particles. The AERONET SSA observations increase, reaching up to $0.90-0.92(0.94-0.96)$ at $440 \mathrm{~nm}(675 \mathrm{~nm})$, values which are more typical of mineral dust (that scatters radiation more efficiently than biomass burning aerosols) as measured during the Dust Outflow and Deposition to the Ocean experiment (DODO) [McConnell et al., 2008]. Although the
SSA of dust aerosols can vary considerably depending on mineral composition (i.e., source region, hematite content) and size distribution [Sokolik and Toon, 1999; Otto et al., 2007; McConnell et al., 2010], the monthly averaged SSA values of RegCM3 represent the mean SSA values retrieved at the different AERONET sites well.

[31] The spectral dependence of SSA is well simulated in April and March, with SSA increasing with wavelength for dust aerosol both in model and AERONET retrievals (Figure 3). This is expected since the model predicts intense dust emissions in these months and since the preset SSA values for the four dust size bins increase with wavelength (Table 2). In December and January, AERONET SSA retrievals also increase with wavelength, but the spectral dependence is weaker due to the presence of BB aerosols, which, conversely to dust have a negative spectral dependence at these wavelengths [Derimian et al., 2008b]. As shown in the Figure 3, the RegCM3 SSA increases too strongly between $440 \mathrm{~nm}$ and $675 \mathrm{~nm}$ during the biomass burning period. This is possibly related to an overestimation of the effective radius of the carbonaceous size distribution used in the Mie calculations or more likely, to an underestimation of the smoke aerosol concentration, compared to dust.

\subsubsection{AOT}

[32] Figure 3 shows that simulated AOT is strongly underestimated at Ilorin and Djougou. Explanations for these differences are uncertain, but it is possibly related to the underestimation of local BB sources which are not accounted for in the inventories. During March and April, AOT at Dakar is correctly estimated, indicating a good export of dust aerosol by easterly winds toward the Atlantic Ocean. At the other sites AOT is strongly underestimated during these 2 months. In this case, it is likely that the underestimation of dust sources in the Sahel contributes to the underestimation of simulated AOT. Indeed, the RegCM3 dust emission scheme is very sensitive to assumptions regarding surface properties of arid soil [Laurent et al., 2008] and the accuracy of the simulated surface wind fields. Todd et al. [2008] have shown that the Bodélé depression, one of the main sources during the dry season, is not properly estimated in RegCM3 due to the underestimation of the magnitude of local winds. Finally, it is also possible that specific land use categories, such as grasslands, might become potential emitters during the dry season but the model does not account for these sources since only desert and semidesert are identified as effective dust sources. The seasonality of the sources is thus not fully accounted for in the RegCM3 dust model since the land use is fixed and does not evolve in space or time. However, the main drivers for dust uplift such as the meteorological conditions, vegetation, and soil moisture are simulated and can modulate the dust emission rates through the year. In addition, it seems that RegCM3 does not accurately represent advection of dust aerosol to more southern latitudes. Konaré et al. [2008] describe a bias in the location of the intertropical front in long-term (30 years) simulations using RegCM3. They noted that the intertropical front is located too far north compared to the NCEP climatology. This bias may partly be responsible for the lack of Harmatan-advected airborne dust aerosols to southern latitudes. In addition, the vertical mixing of aerosols may have also an impact on the 

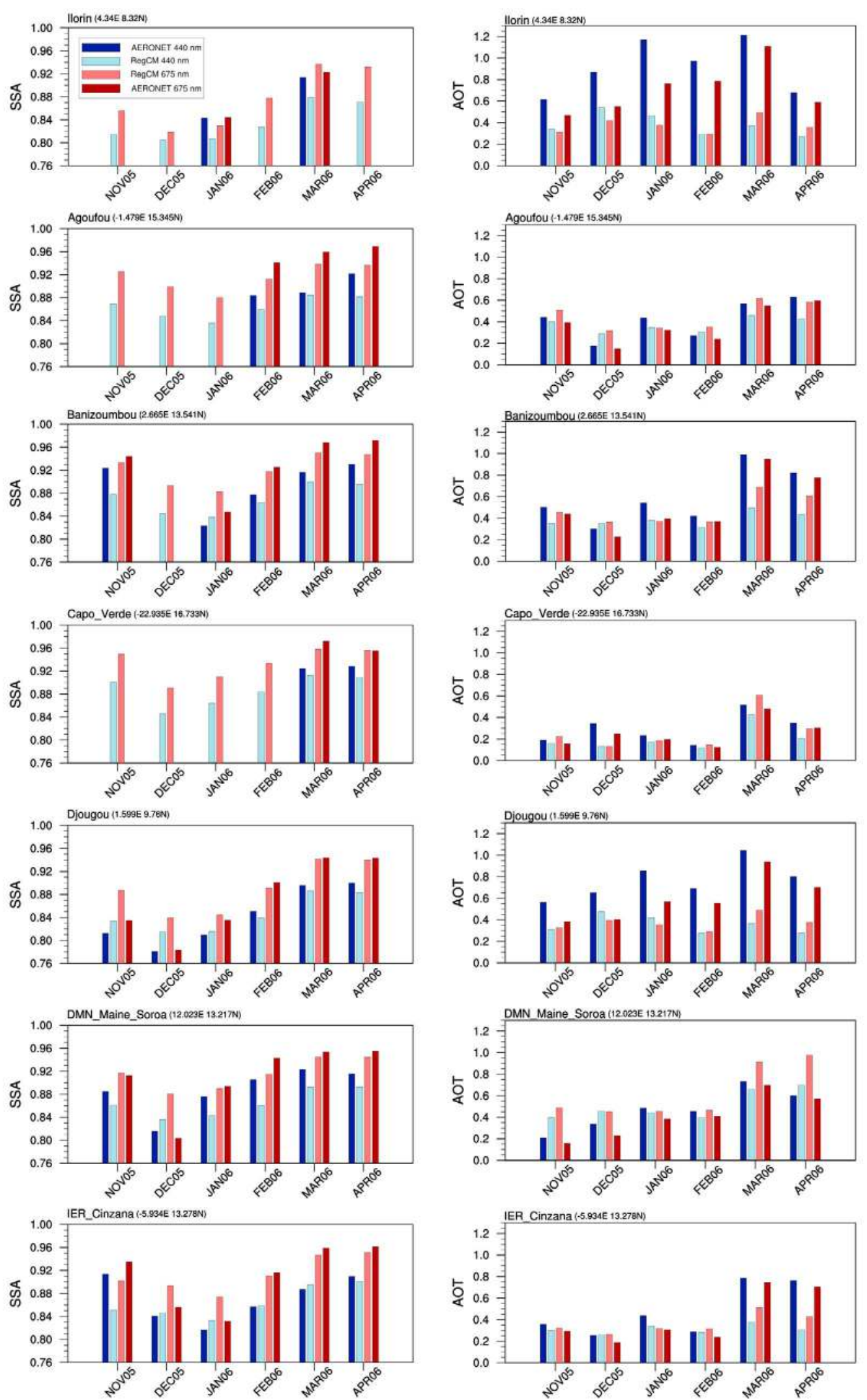

Figure 3. Time series of monthly averaged (left) SSA and (right) AOT from AERONET measurements and RegCM3. Values of AOT and SSA are indicated at $440 \mathrm{~nm}$ (blue) and $675 \mathrm{~nm}$ (red) simulation. 

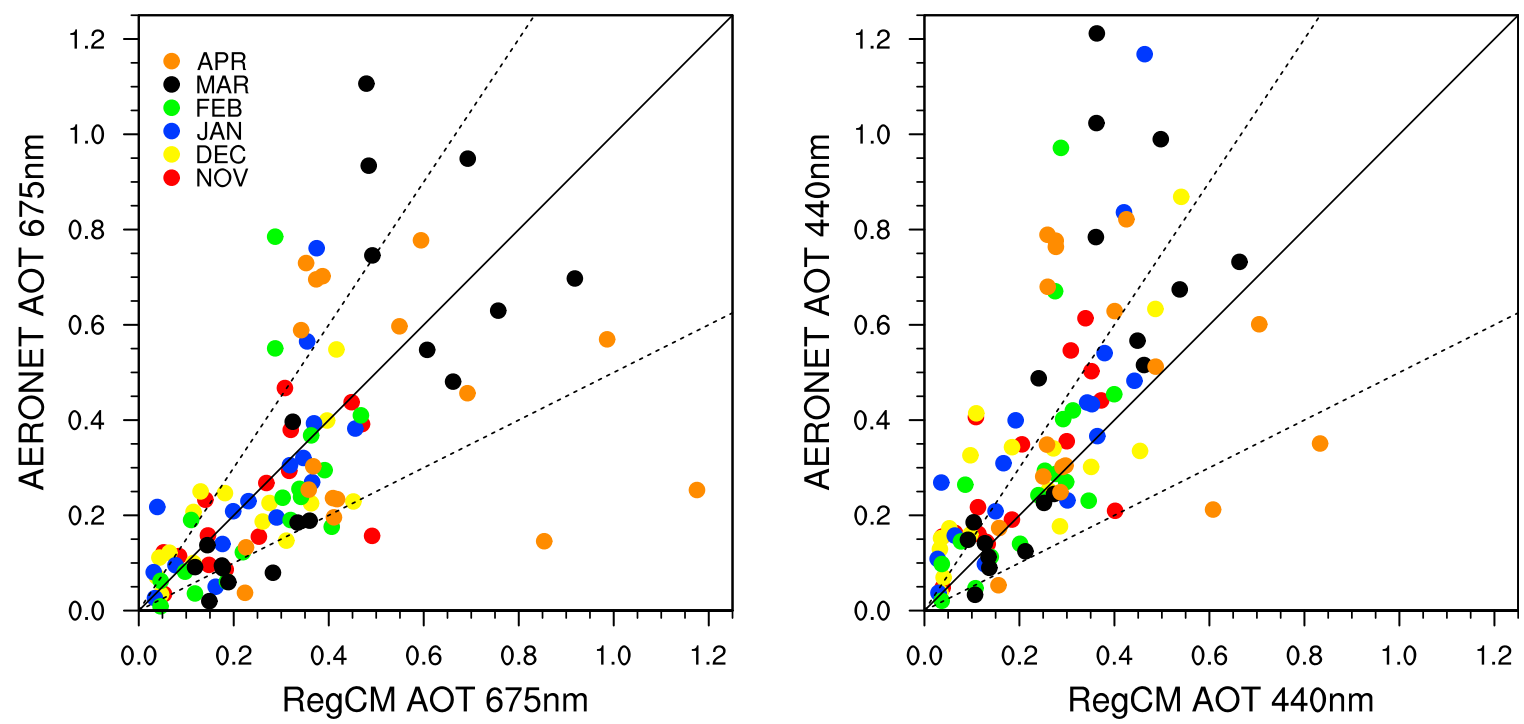

Figure 4. Scatterplot of RegCM3 versus AERONET level2 monthly averaged AOT at (left) $675 \mathrm{~nm}$ and (right) $440 \mathrm{~nm}$. Plain line represents the curve $y=x$, and the dashed lines represent the curves " $y=x \pm x \times 0.5$."

horizontal dispersion. In this regard, comparison of RegCM3 aerosol extinction profiles with LIDAR data are discussed in section 3.2. Thanks to Figure 4, we can note that at $675 \mathrm{~nm}(440 \mathrm{~nm})$, the correlation coefficient from a linear regression between modeled and measured AOT is 0.30 (0.34). It appears that AOT in March and April are the least well simulated by RegCM3 probably due to some weakness in the dust uplift in the model, and the location of the main sources of dust as previously mentioned above. On average, RegCM3 tends to underestimate (overestimate) AOT at $675 \mathrm{~nm}$ (at $440 \mathrm{~nm}$ ).

[33] The spectral dependence of AERONET AOT is more pronounced in AERONET AOTs during the period of the peak of BB aerosol emission compared to the March-April period (Figure 3). This is consistent with the fact that for these months, the aerosol burden is composed mostly of biomass burning aerosols (fine particles with stronger AOT spectral dependence than coarser aerosols [Eck et al., 1999]), whereas in March and April dust dominates the atmospheric aerosol burden. The RegCM3 AOT shows a similar trend during December and January (with AOT decreasing as wavelength increases) for most of the AERONET sites. In contrast, in March and April, RegCM3 AOT increases with wavelength while the AERONET AOT decreases with wavelength. This discrepancy can be explained by a misrepresentation of the dust size distribution. In RegCM3 the parameterization of Alfaro and Gomes [2001] is used to simulate the size distributed dust emission flux. Laurent et al. [2008] have suggested that parameters used in the Alfaro and Gomes [2001] scheme are not well constrained regionally and recommend using a fixed size distribution instead. The fine mode could in our case be overestimated, which may explain the behavior of the model. Indeed the first bin tracer is assigned a mass extinction coefficient of $1.89 \mathrm{~m}^{2} / \mathrm{g}$ and $2.93 \mathrm{~m}^{2} / \mathrm{g}$ (Table 1) at $440 \mathrm{~nm}$ and $675 \mathrm{~nm}$ respectively, which may significantly influence the simulated spectral dependence. Moreover, the weak resolution of the wind fields used for the dust emission simulations, or the number of size bins could be inadequate to represent dust transport correctly, giving too much weight to the dust burden in the first bin, and contribute to the discrepancy between simulated and observed AOT.

\subsubsection{Comparisons of RegCM3 Simulated AOT} With Satellite Retrievals

[34] Figures 5a and $5 \mathrm{~b}(5 \mathrm{c}$ and $5 \mathrm{~d})$ present spatial maps of AOT from MISR at $555 \mathrm{~nm}$ and RegCM3 at $495 \mathrm{~nm}$ (MODIS AQUA at $550 \mathrm{~nm}$ aqua and RegCM3 at $495 \mathrm{~nm}$ ) averaged over the DJF period. In order to compare only pixels that have been sampled by the satellite, the daily RegCM3 AOT are aggregated at the resolution of the satellite measurements and masked when daily satellite AOT pixels have no value. This explains why there are missing values in the simulated AOT maps (Figures 5b and 5d). PARASOL fine mode AOT (Figure 5e) and PARASOL total AOT over oceans (Figure 5f) are also plotted. In order to compute the fine mode AOT at $500 \mathrm{~nm}$, we used the 865$500 \mathrm{~nm}$ Angström exponent provided by the PARASOL retrieval algorithm.

[35] On average, the RegCM3 AOT is higher than the satellite estimations. Regional mean AOT over the subdomain $50^{\circ} \mathrm{S}-15^{\circ} \mathrm{N}$ and $10^{\circ} \mathrm{W}-30^{\circ} \mathrm{E}$ for MODIS aqua, MISR, PARASOL and RegCM3 is about $0.34,0.37,0.39$ and 0.40 (at $495 \mathrm{~nm}$ ), respectively. Over the gulf of Guinea and the Atlantic, retrieved AOT for the 3 different satellites products provide values in the same range, both in terms of amplitude $(\sim 0.3-0.6)$ and spatial distribution (Figures 5a, $5 b$, and 5f). RegCM3 AOT is in very good agreement for this area. In contrast, over central Africa there is significant disagreement between simulated and retrieved AOT. RegCM3 AOT are approximately or greater than 1 (at $495 \mathrm{~nm}$ ) while MODIS and MISR products show values between 0.3 and 0.5 (at $\sim 550 \mathrm{~nm}$ ). The simulated AOT maximum coincides with the area of maximum emissions in the biomass burning inventories and to a hot spot of high biomass fuel load. In the 
MISR AOT $555 \mathrm{~nm}$

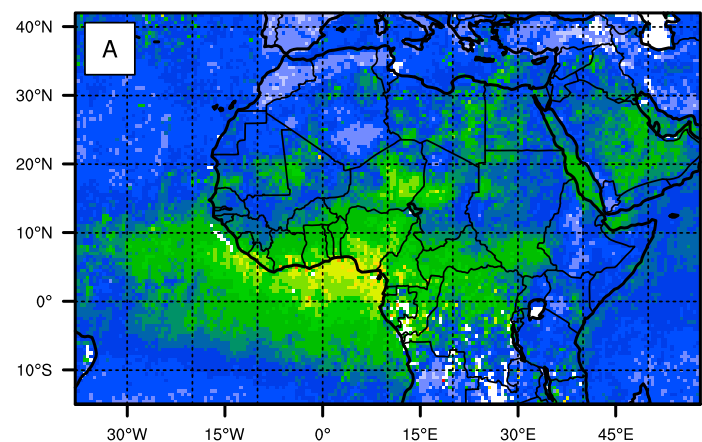

MODIS TERRA AOT $550 \mathrm{~nm}$

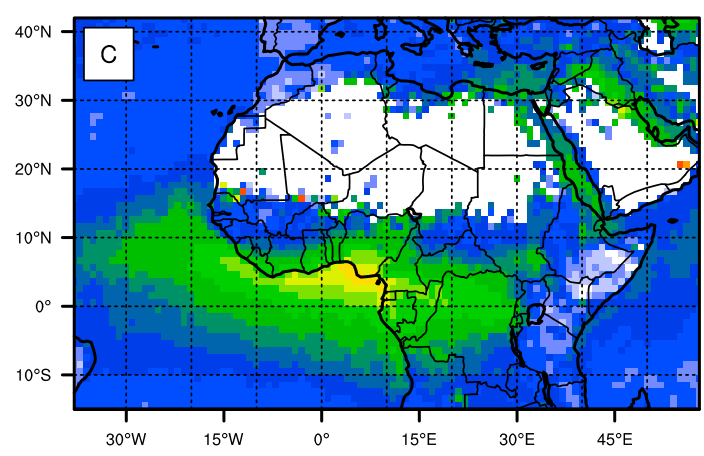

PARASOL AOT $500 \mathrm{~nm}$

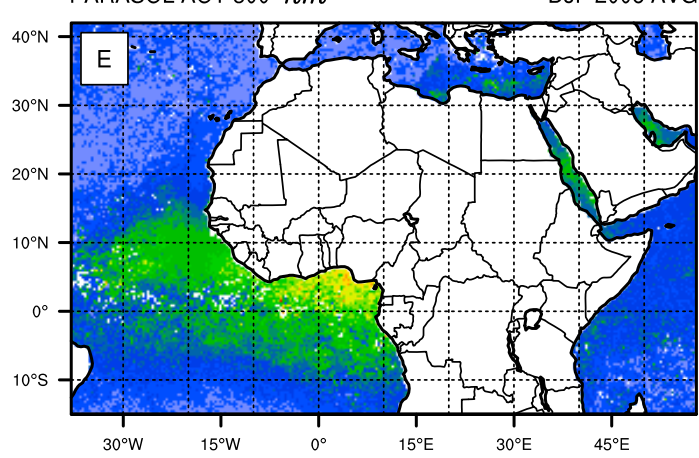

MOPITT surface $\mathrm{CO}[p p b v]$

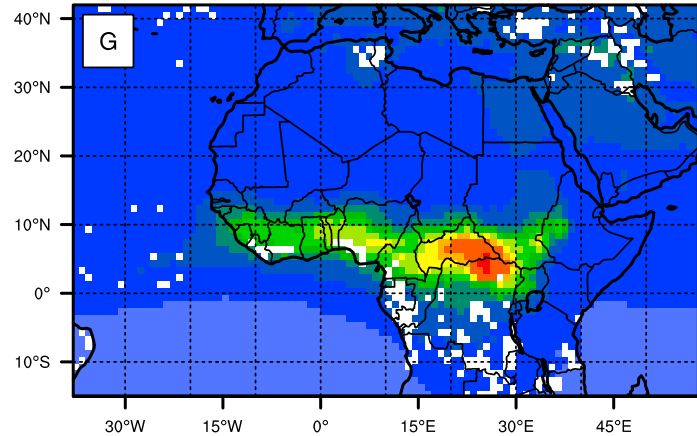

RCM AOT $495 \mathrm{~nm}$

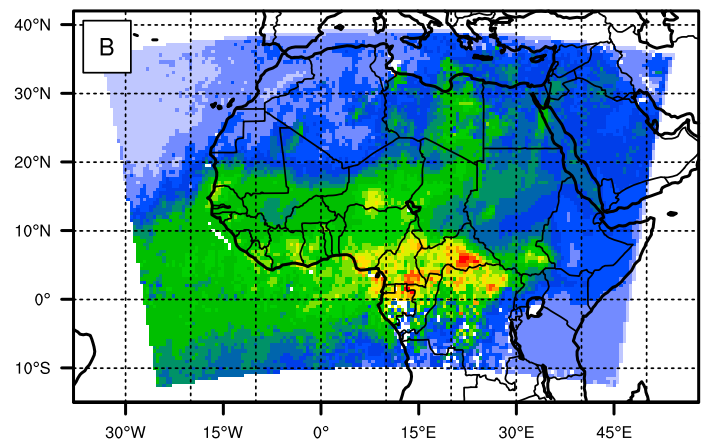

RCM AOT $495 \mathrm{~nm}$

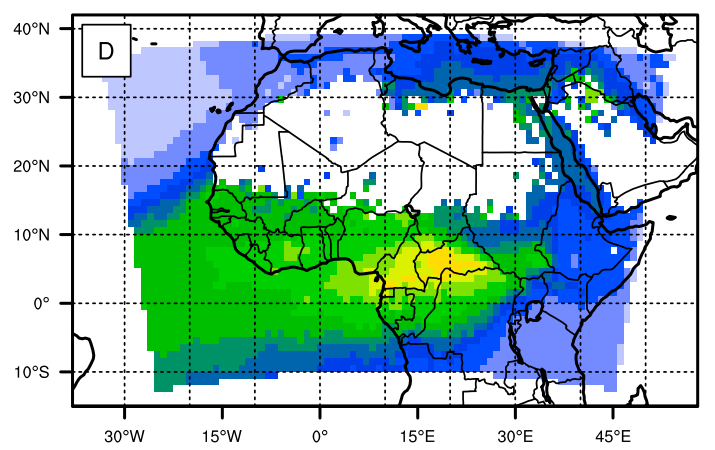

PARASOL FINE MODE AOT $500 \mathrm{~nm}$

DJF 2006 AVG
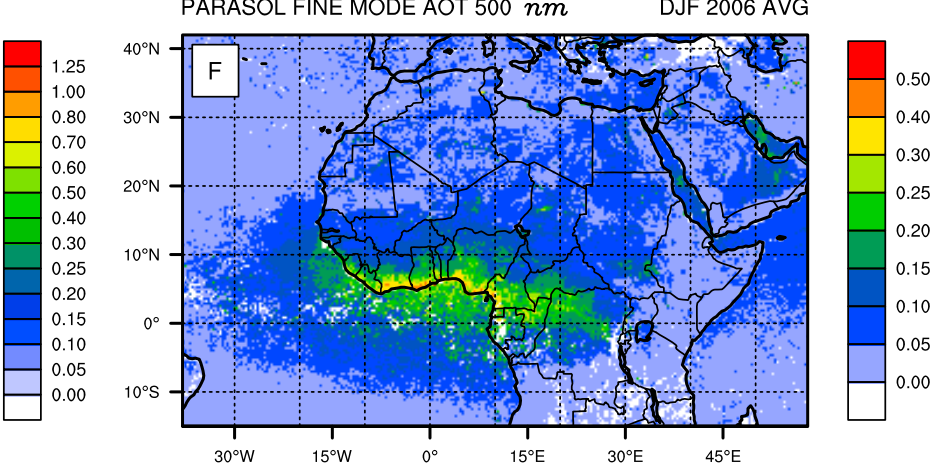

MOPITT column CO $\left[\mathrm{mol} / \mathrm{cm}^{2}\right]$

DJF 2006 AVG

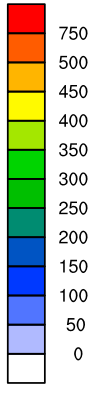

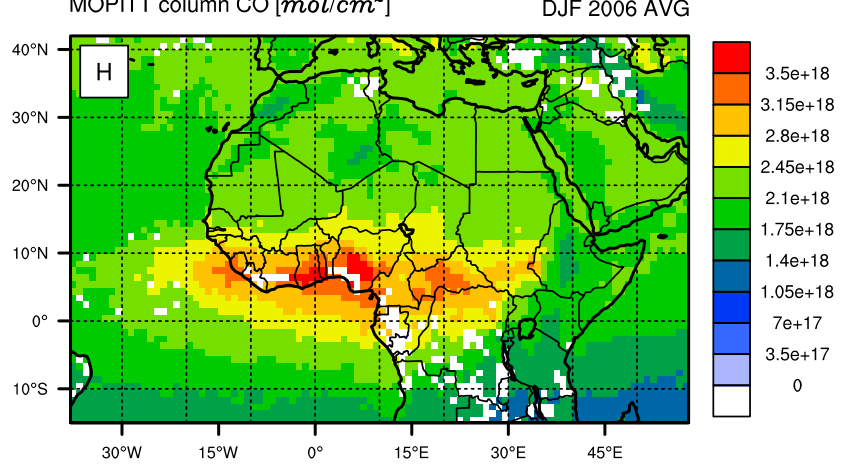

Figure 5. December-January-February (DJF) averaged (a) MISR AOT at $555 \mathrm{~nm}$, (b) RegCM3 AOT at $495 \mathrm{~nm}$, (c) MODIS terra AOT at $550 \mathrm{~nm}$, (d) RegCM3 AOT at $495 \mathrm{~nm}$, (e) PARASOL total AOT at $500 \mathrm{~nm}$, (f) PARASOL fine mode AOT at $500 \mathrm{~nm}$, (g) MOPITT surface CO concentration, and (h) MOPITT column CO burden. 
satellite products, on the other hand, maximum of AOT is located over gulf of Guinea. Similar spatial disagreements between satellite retrieved AOT and modeled AOT have also been reported by Johnson et al. [2008a], Myhre et al. [2008] and Liousse et al. [2010] who used different models and inventory data sets. Similarly Tummon et al. [2010] also observed such disagreements over southern Africa using both the GFEDv2 inventory [van der Werf et al., 2006] and the bbAMMA inventories used in the present study.

[36] It is also important to note that over the tropical Atlantic Ocean south of the equator, modeled AOT tends to be higher than in the satellite retrievals. This may illustrate some model weakness in terms of transport of aerosol in the outflow (may be a too diffusive advection scheme) or some underestimation of dust sources along the coast.

[37] Since the carbon monoxide (CO) is a robust tracer for combustion, it can be used as a proxy for detecting areas of important emission of carbonaceous aerosol. In this study, we have used $\mathrm{CO}$ as a proxy to study the location of biomass burning sources. As it is quite difficult to dissociate biomass burning and anthropogenic sources, we only discuss retrievals obtained over central Africa and not within advected regions. DJF average $\mathrm{CO}$ concentrations at the surface as retrieved from MOPITT are shown in Figure 5h. Over central Africa, the MOPITT CO maximum clearly corresponds to the maximum observed in RegCM3 AOT map. The high values of $\mathrm{CO}$ surface and column concentrations indicate biomass burning over central Africa, however, this signature is not apparent in the satellite AOT retrievals. This indicates that the satellite retrieval probably underestimates AOTs over this part of the continent.

[38] In addition, we consider the PARASOL fine mode AOT (Figure 5f). The fine mode is used to distinguish anthropogenic aerosols (e.g., carbonaceous aerosols from pollution and/or combustion) from natural aerosols (mainly dominated by coarse aerosols such as mineral dust or sea salt). Maximum AOT values along the gulf of Guinea can clearly be distinguished, with a few sparse hot spots close to the coast. The locations of these high-AOT spots are suggestive of significant anthropogenic aerosol emission sources. An important area of high fine-mode AOT ( $\sim 0.2$ at $500 \mathrm{~nm})$ covering southern Central Africa, the northern Democratic Republic of the Congo and the north of Cameroon can also be identified. This zone is close to the area of maximum emission in the bbAMMA inventories and surface concentration of $\mathrm{CO}$ (Figure 5h). This reinforces the idea that an important amount of particulate matter is released in this area and that emission inventories correctly identify the location of intense emissions of BB aerosols.

[39] The eastward shift between simulated and MODIS or MISR total AOT may result from a combination of errors from both model and satellite retrieval algorithms. AOT is complicated to retrieve over land as a result of high surface reflectance and significant heterogeneity of land use types. In addition, cloud cover which obscures the satellite signal, is likely important in the vicinity of the intertropical convergence zone (and also over land where moist convection is frequent). These issues may impact the number of cloudfree observations and may result in some biomass burning events being missed or bias being introduced into the average AOT signal (i.e., estimations of AOT in areas with few samples are less confident than for those areas fre- quently sampled). The misidentification of thick aerosol plumes as clouds by the cloud-screening algorithms can also occur. This issue has already been reported by Haywood et al. [2003] in the case of the SHADE campaign during dust storm. Myhre et al. [2004] showed that cloud-screening algorithms can be one of the major sources of uncertainty in AOT estimations from remote sensing. This can explain disappearances why high AOT over central Africa is seen in the model but not in the observations.

[40] There could also be some model deficiencies related to tracer transport and aerosol removal. For instance, Pelon et al. [2008] studied transport processing of smoke aerosols during the strong event of biomass burning occurring during the 19 to 24 January 2006 period. They concluded that the biomass burning aerosols emitted close to the intertropical discontinuity are transported in the trade wind layer above the boundary layer and then advected over the ocean where they could accumulate. The position and the dynamics of the monsoon flux during the dry season could lead to efficient vertical transport of biomass burning aerosols above boundary layer as for dust aerosols during the wet season. The integrated MOPITT CO measurements (Figure 5f) exhibit a pattern that may support this hypothesis. The integrated $\mathrm{CO}$ has a horizontal distribution centered over the gulf of Guinea, which contrasts with the surface $\mathrm{CO}$, which is located in central Africa as mentioned above. This signal is not simulated by RegCM3. Potential errors due to the horizontal and vertical aerosol transport linked to simulated convective processes therefore cannot be excluded. This last process can be too weak, and thus too little aerosol is transported into the middle troposphere, whereas the advection scheme is known for being too diffusive.

[41] In addition, the dry and wet deposition velocity constant used for BC and OC tracers may not be representative of the region. Important uncertainties remain regarding these parameters and may strongly affect the simulated burden of aerosol within the atmosphere.

[42] Finally, other aerosols sources may not be taken into account in RegCM3. African mega cities are known as important sources of anthropogenic pollution [Lawrence et al., 2007]. These sources do not seem to be correctly estimated in the fossil fuels and biofuels emission data set of Junker and Liousse [2008] [Assamoi and Liousse, 2010] and this may partly explain the low simulated AOT values along the Guinean cost. This particularly appears to be the case in the vicinity of Lagos, Nigeria, where the city population increased from 1.7 million in 1975 to about 10.9 million in 2005 , and is projected to be the most populous city in Africa and the eleventh in the world by 2015 [United Nations, 2005] with about 16 million inhabitants. Gas and particulate matter emissions from this megacity are significant and may impact the air quality at scales larger than the urban scale. Furthermore, emissions of carbonaceous aerosols from petrochemical industries located in this area are not considered in current fossil fuel inventories and may also be an important source of gases and absorbing aerosols.

\subsection{Vertical Profiles of Aerosol Extinction}

[43] Recent studies investigating the influence of the direct aerosol radiative effect on the regional circulation, temperature and precipitation over West Africa do not consider the vertical aerosol profiles. Sud et al. [2009] 
(a) Niamey $\{2.172 \mathrm{~N} 13.481 \mathrm{E}\} \quad$ Jan 2006

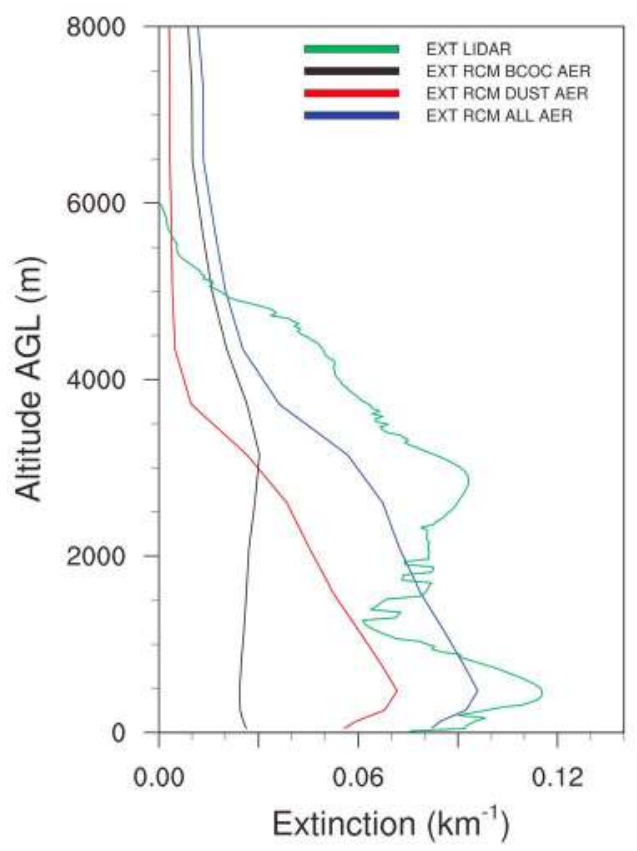

(b) MBour $\{-16.95 \mathrm{~N} 14.35 \mathrm{E}\} \quad$ Jan 2006

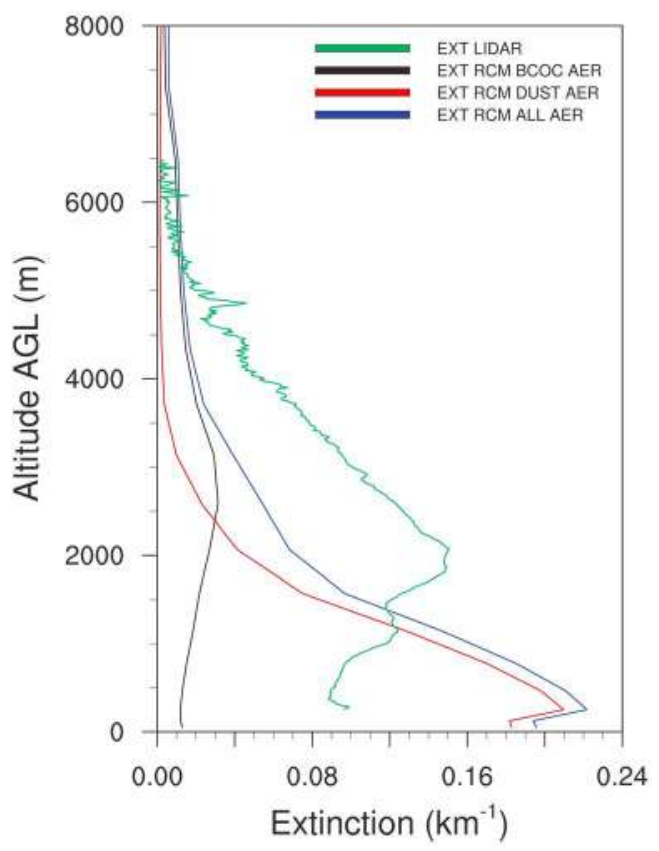

Figure 6. Monthly averaged aerosol extinction profiles at $532 \mathrm{~nm}$ (in $\mathrm{km}^{-1}$ ) for January at (a) Niamey and (b) Mbour.

investigated the effects of the direct and indirect aerosol forcing on the regional climate over Africa by using the GEOS-4 GCM, but do not report any comparisons of the aerosol profiles (despite the high vertical resolution of the model, with 55 vertical levels). In parallel, Lau et al. [2009] used the NASA finite volume general circulation model (fvGCM) to explore the responses of dust radiative forcing on the water cycle and again they do not mention any comparisons of vertical aerosol profiles. It should be noted that the complex vertical profile of atmospheric aerosol over the West African region (BB particles situated above a dusty layer) has been highlighted in the framework of the recent AMMA SOP-0 experiment [Haywood et al., 2008; Pelon et al., 2008; Kim et al., 2009]. One of the objectives of this study is therefore to investigate whether the RegCM3 model is able to capture this characteristic.

[44] Recent in situ observations from the AMMA/DABEX campaigns have improved our understanding of the aerosol properties and transport over West Africa. A typical aerosol extinction profile observed during the dry season consists of a low-level layer dominated by dust aerosols advected by the Harmatan. The dust extinction decays rapidly above $2 \mathrm{~km}$ and reaches values close to zero around 5 or $6 \mathrm{~km}$. A thicker layer generally observed at altitudes between 2 and $5 \mathrm{~km}$, is found above the dry dusty layer and is dominated by biomass burning aerosols which originate from long-range transport in the trade wind layer [Haywood et al., 2008; Kim et al., 2009]. The vertical profile of aerosols may influence the radiative forcing of particles, in particular if absorbing aerosols overlay reflective layers such as low-level clouds or dust layer [Johnson et al., 2004, 2008a; Pinker et al., 2010; Zarzycki and Bond, 2010]. Johnson et al. [2008a] showed that the presence of mineral dust in the lower layers of the atmosphere could act as a slight enhancement of the surface albedo, thereby enhancing the absorption of solar radiation by the biomass burning layer up to $10 \%$. Similarly, BB aerosol layers can be observed above low-level clouds with high albedo in the gulf of Guinea [Pelon et al., 2008; Mallet et al., 2009]. Therefore it is essential to simulate correctly not only the aerosol optical properties but also the vertical stratification of these aerosols in order to assess the direct radiative forcing of the mixture of dust and smoke aerosols.

[45] Figure 6 presents the monthly averaged extinction profile for January 2006 is represented. The green curves correspond to the extinction profiles derived from MPL measurements at Niamey [McFarlane et al., 2009] and Mbour [Léon et al., 2009]. At Niamey, two marked maxima are observed in the LIDAR profiles. The extinction profile peaks near $500 \mathrm{~m}$ due to dust aerosols, and again near $3 \mathrm{~km}$ in a layer dominated by biomass burning aerosols. The RegCM3 profile agrees reasonably well with the observations, although the dust profile (in red) is probably underestimated in the first kilometer at the Niamey site. At Mbour, the model reproduces a similar vertical structure of the extinction profile, although the dust extinction is stronger in the lower atmospheric levels. For January 2006, an important amount of BB aerosols was advected to Mbour, in particular during the so-called "golden days" after 19 January 2006 [Derimian et al., 2008a; Pelon et al., 2008]. The simulated extinction profiles are significantly underestimated for this period, indicating that the long-range transport of $\mathrm{BB}$ aerosols is too weak or, that the emission inventories used in this study underestimate some important sources of smoke aerosols in western part of the Sahel for this month. 
[46] In the following months, dust aerosol is the main aerosol species observed in the atmosphere. A more systematic comparison of RegCM3 aerosol extinction profiles with MPL measurements for the months following the biomass burning season (not shown) reveals that dust extinction is usually strongly underestimated at Niamey while it is in better agreement at Mbour. It seems that at Mbour which is closer to the dust source regions than Niamey, the model tends to over predict the dust extinction, suggesting an overestimation of dust emission. However, away from those sources RegCM3 seems to get the dust transport low, which could explain the underestimation of dust extinction at Niamey. The vertical stratification is excellent at Mbour while at Niamey, the dust aerosol extinction profiles are more dispersed in the vertical column. As mention in section 3.1, it is possible that the model simulates the Inter Tropical Front (ITF) too far north, resulting in too much vertical dispersion of dust aerosol. A lack of coarse mode aerosol due to an unrealistic aerosol size distribution at the source, or an underestimation of local sources may also contribute to this underestimation of dust aerosol in the lowest layers.

[47] Briefly, we can conclude that despite the coarse vertical resolution and the use of a quite simple vertical tracer transport parameterization, RegCM3 can capture the first-order aerosol vertical stratification, and the aerosol layering (BB layer located above the dust one) is reasonably well reproduced by the model. However, the low-level dust loading could, on average be underestimated, particularly at Niamey.

\subsection{Aerosol Direct Radiative Forcing}

\subsubsection{Radiative Forcing at TOA and SRF}

[48] The clear-sky direct radiative forcing (DRF) for DJF has been estimated at TOA and at the surface (SRF). The shortwave radiative forcing of aerosol at the surface is defined as the difference in net flux:

$$
S R F_{S W R F}=\left(S W_{A E R}^{\downarrow}-S W_{C L E A R}^{\downarrow}\right)-\left(S W_{A E R}^{\uparrow}-S W_{C L E A R}^{\uparrow}\right),
$$

where $S W_{A E R}^{\downarrow}\left(S W_{A E R}^{\hat{1}}\right)$ is the downward (Upward) shortwave radiative fluxes $\left(\mathrm{W} / \mathrm{m}^{2}\right)$. Similar conventions are adopted at TOA and for LW regime. In addition, the atmospheric direct forcing (ATM) is defined as the divergence between the direct radiative forcing at TOA and at the surface.

[49] The LW DRF by dust aerosols is also accounted for by considering the dust absorptivity/emissivity [Stephens, 1984]. This kind of parameterization neglects the scattering of LW radiation, which may underestimate the overall LW forcing by up to $50 \%$ at TOA and $15 \%$ at the surface [Dufresne et al., 2002]. In the future, RegCM developments are scheduled regarding the LW parameterization that should be able to account for these effects. The LW forcing produces positive forcing at the SRF as a result of the additional downward flux from the aerosol layer. At the TOA the outgoing LW radiation is, in most cases, decreased by the aerosol loading, except in the case of a strong inversion, when the temperature of the aerosol layer is higher than the surface temperature [Markowicz et al., 2003]. In addition, LW direct radiative forcing at the SRF is generally larger than at TOA [Slingo et al., 2006], leading to a negative LW divergence (enhanced LW cooling) within the atmosphere.

[50] Figure 7 presents the SW + LW daily clear-sky DRF at the TOA and the SRF averaged for the DJF period. We performed a reference simulation (REF) that includes all aerosol species and two additional simulations: a DUSTex simulation where only dust aerosols are considered and a BCOCex simulation, where only carbonaceous aerosols are considered. Figure 8 shows the relative contribution of carbonaceous aerosol to the total extinction. The DRF are reported in the Table 3a. We compute the DRF over different subregions of the West African domain in order to take into account the influence of the different surface albedos that can be encountered above vegetation, desert and ocean. The subdomains are presented in Figure 7c (red boxes). The DRF efficiency (i.e., the direct radiative forcing normalized by the AOT at $500 \mathrm{~nm}$ ) is also reported (Table 3b). The DJF average aerosol SSA at $500 \mathrm{~nm}$ calculated over the respective subdomains (for the REF simulation) is also reported in Table $3 a$ and Table $3 b$.

[51] The DRF at the TOA, due to the mixture of aerosols, is negative over dark surfaces (ocean, land with vegetation), with values ranging between -4 and $-8 \mathrm{~W} \mathrm{~m}^{-2}$. It becomes positive over bright surfaces such as desert, reaching up to 2.5-5 $\mathrm{W} \mathrm{m}^{2}$ (i.e., increased energy kept into the "surfaceatmosphere" system). The values obtained above the gulf of Guinea are slightly lower than reported by Johnson et al. [2008a] (from a 3 year average of the month of January) or Myhre et al. [2008] (averaged between approximately January and February 2006) who estimated a TOA DRF of approximately double our value. A strong reduction of the incoming solar radiation at the surface is observed in the Sahelian belt (around -20 to $-60 \mathrm{~W} \mathrm{~m}^{-2}$ ).

[52] We estimated an averaged surface DRF of $-28.27 \mathrm{~W}$ $\mathrm{m}^{-2}$ in the Sahel region and a TOA DRF of $-3.87 \mathrm{~W} \mathrm{~m}^{-2}$ (Table 3a), leading to an ATM DRF of $24.4 \mathrm{~W} / \mathrm{m}^{2}$. This compares well with work by Raut and Chazette [2008], who found an average TOA DRF of $-1.4 \mathrm{~W} \mathrm{~m}^{-2}$ at Niamey for five case studies (between 26 January 2006 and 1 February 2006) and a mean ATM DRF of $19.8 \mathrm{~W} \mathrm{~m}^{-2}$ (AOD 0.4 at $500 \mathrm{~nm}$ in their study).

[53] From radiative transfer calculations, Mallet et al. [2008] reported a DRF efficiency at surface (TOA) of $-57.9 \mathrm{~W} \mathrm{~m}^{-2} / \mathrm{AOT}_{500 \mathrm{~nm}}\left(-17.5 \mathrm{~W} \mathrm{~m}^{-2} / \mathrm{AOT}_{500 \mathrm{~nm}}\right)$ at Djougou for the period 17-24 January. RegCM3 estimations at the surface $\left(-61.0 \mathrm{~W} \mathrm{~m}^{-2} 2 / \mathrm{AOT}_{500 \mathrm{~nm}}\right)$ in the "Sahel" subregion compare well with this value, although the TOA DRF forcing is slightly underestimated $\left(-8.35 \mathrm{~W} \mathrm{~m}^{-2} /\right.$ $\left.\mathrm{AOT}_{500 \mathrm{~nm}}\right)$. The estimated ATM DRF efficiency is $52.64 \mathrm{~W} \mathrm{~m}^{-2} / \mathrm{AOT}_{500 \mathrm{~nm}}$.

[54] The effect of albedo can be seen in the BCOCex simulation. The ATM DRF efficiency is about $\sim 68 \mathrm{~W} \mathrm{~m}^{-2}$ / $\mathrm{AOT}_{500 \mathrm{~nm}}$ in the "Oceans" and "Sahel" subregions, while it is $80.42 \mathrm{~W} \mathrm{~m}^{-2} / \mathrm{AOT}_{500 \mathrm{~nm}}$ over "Desert" subregion. The enhanced reflection of SW radiation above the bright surface leads to more absorption of solar radiation in the biomass burning aerosol layer.

[55] It is interesting to note, however, that when all aerosols are considered (REF simulation), the ATM absorption efficiency is stronger over the "Sahel" subregion than over the "Desert" subregion $\left(52.64 \mathrm{~W} \mathrm{~m}^{-2} / \mathrm{AOT}_{500 \mathrm{~nm}}\right.$ 

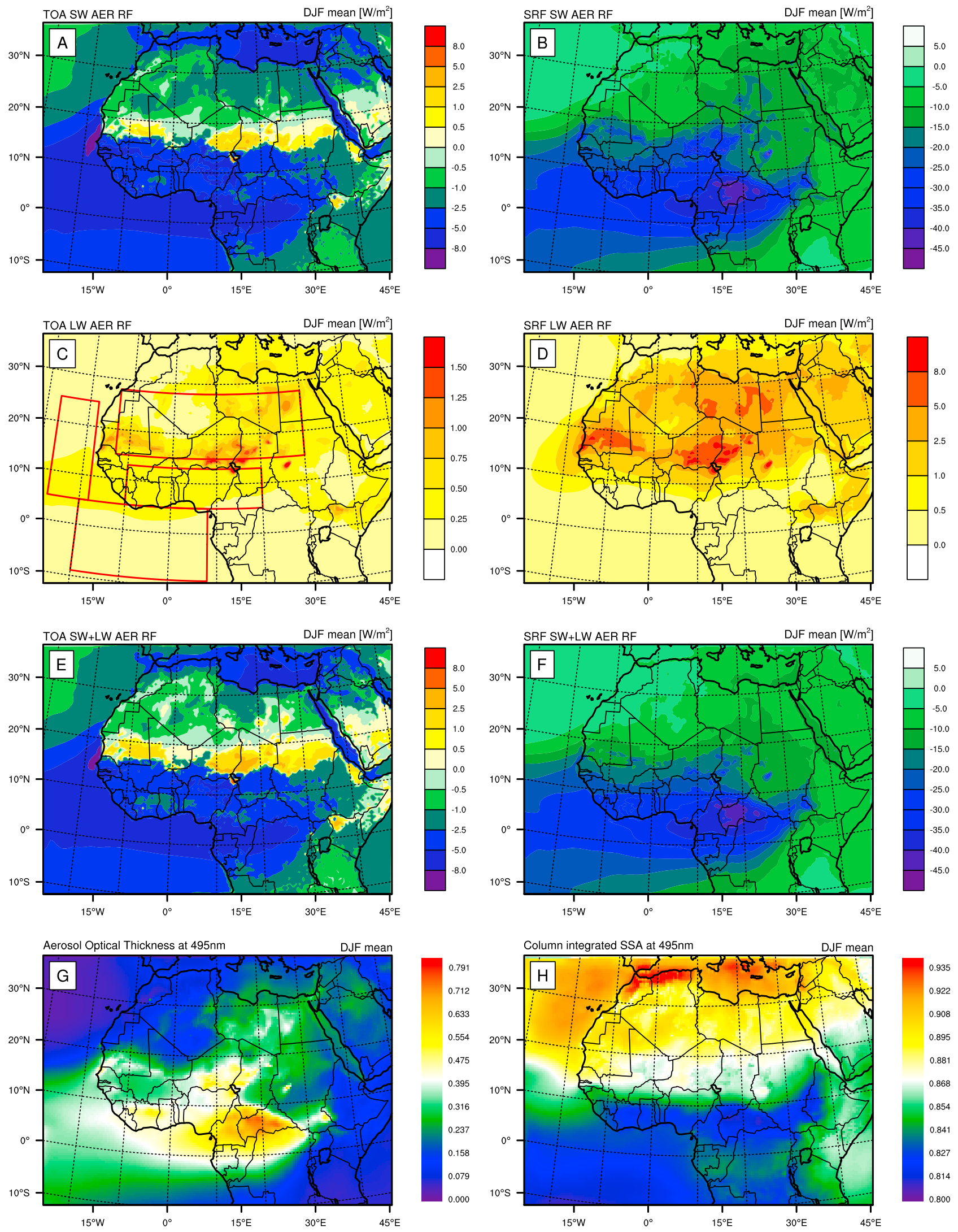

Figure 7. Regional clear sky aerosol radiative forcing for DJF at (a) top of the atmosphere in the SW, (c) the LW, and (e) SW+LW, and at (b) surface in the SW, (d) the LW, and (f) SW+LW, and (g) DJF AOT at $495 \mathrm{~nm}$ and (h) DJF column SSA at $495 \mathrm{~nm}$. Red boxes illustrate the subdomain retained for computing the averaged aerosol direct forcing mentioned in Tables $3 \mathrm{a}, 3 \mathrm{~b}, 4 \mathrm{a}$, and $4 \mathrm{~b}$. 


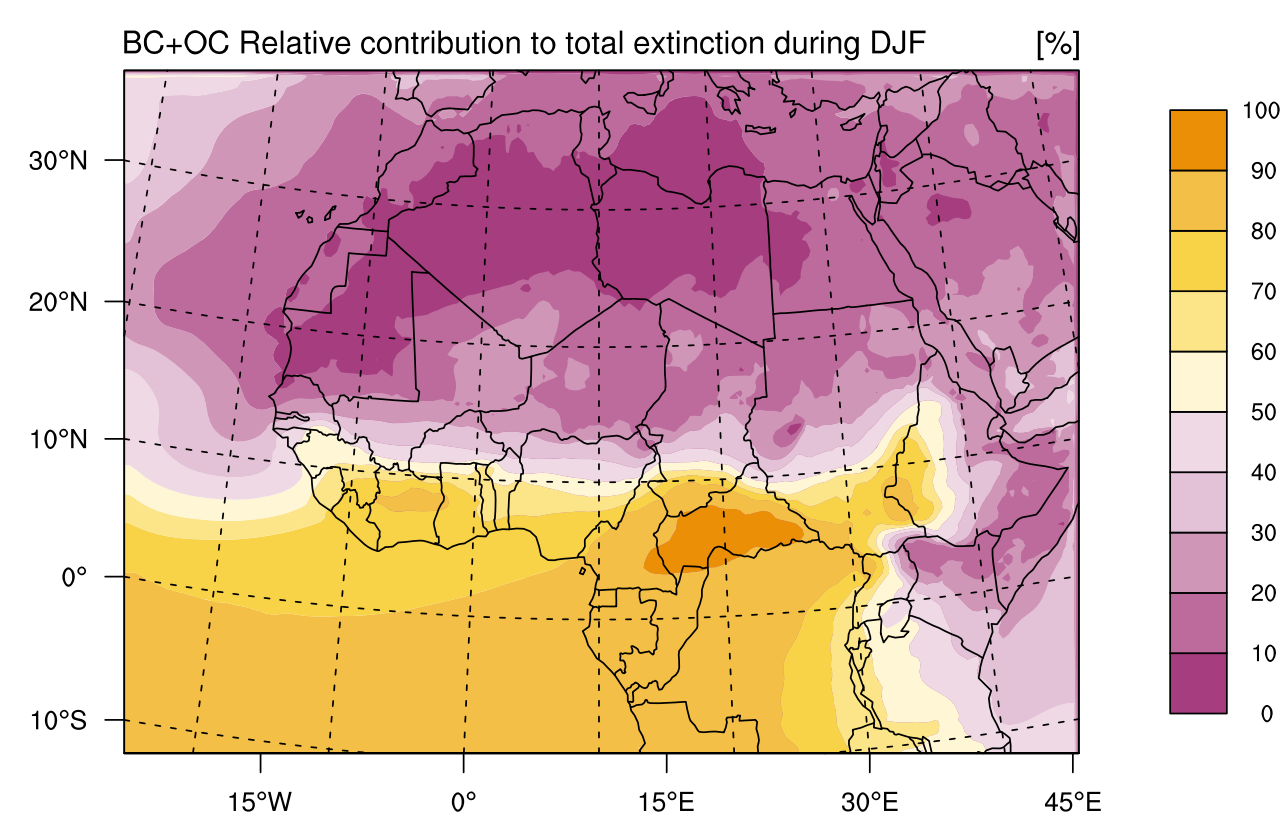

Figure 8. Relative contribution of carbonaceous aerosol to the total extinction for DJF.

versus $37.61 \mathrm{~W} \mathrm{~m}^{-2 /} \mathrm{AOT}_{500 \mathrm{~nm}}$, Table $4 \mathrm{~b}$ ). This can be explained by the combination of the dust effects in the LW regime. Dust aerosols emit radiation downward to the surface, an effect which is more important in the "Desert" subregion because of the greater concentration of dust aerosol in this area. In addition, the SSA of the dust aerosols over the "desert" subdomain is lower (more absorbing) than over "Sahel" subregion. It illustrates that, the concentration of coarse dust aerosols are higher close to dust source (i.e., lower SSA) compared to remote regions (higher SSA due to the absence of coarse dust particles). The mean SSA in the DUSTex simulation is 0.939 over in "Sahel" subregion whereas it is 0.917 in the "Desert" subregion (Tables 3a and $3 \mathrm{~b}$ ). This result is consistent with the work of McConnell et al. [2008], who showed that the inclusion of coarse mineral dust decreases SSA (in the visible range) from 0.99 (fine mode only) to 0.90 (bulk aerosol).

\subsubsection{Sensitivity to Aerosol Optical Properties}

[56] The SSA of biomass burning aerosols can vary greatly depending on the type of burnt vegetation and the meteorological conditions. Johnson et al. [2008a] reported SSA values spanning from 0.73 to $0.93( \pm 0.05)$ with a mean value of 0.81 for aged BB aerosols. Because SSA controls the absorption of SW and LW radiation, it is important to consider the sensitivity of the radiative forcing to this optical parameter. In that context, we performed several sensitivity experiments varying the SSA of $\mathrm{BC}$ and $\mathrm{OC}$. In the reference (REF) simulation, we used the values of SSA mentioned in Table 1. In simulations SSAm10 (and SSAp10) we decreased (increased) the SSA of $\mathrm{BC}$ and $\mathrm{OC}$ by $10 \%$ in order to cover the range of SSA measured during DABEX. The new estimations of aerosol radiative forcing are reported in Tables $4 \mathrm{a}$ and $4 \mathrm{~b}$. The total SSA for the mixture of carbonaceous aerosols and dust aerosol in the REF simulation is about 0.83 over the gulf of Guinea while in the SSAm10 and SSAp10 simulations it is 0.78 and 0.88 , respectively, for the DJF season. In terms of the DRF, the deviation from the REF simulation is $\pm 2.25 \mathrm{~W} \mathrm{~m}^{-2}$ at the TOA. This value is significant compared to the magnitude of estimated TOA DRF of $-3.87 \mathrm{~W} \mathrm{~m}^{-2}$, and illustrates that the uncertainty of about $10 \%$ on the aerosol absorbing properties can result in an uncertainty greater than $50 \%$ in terms of the TOA DRF. Over the ocean, the uncertainty in terms of the TOA DRF is also significant, but not as large as over vegetated land. Over the desert, the TOA DRF reverses from negative values $\left(-0.20 \mathrm{~W} \mathrm{~m}^{-2}\right.$ and $-0.82 \mathrm{~W} \mathrm{~m}^{-2}$ in the REF and SSAp10 simulations, respectively) to a positive value $\left(+0.625 \mathrm{~W} \mathrm{~m}^{-2}\right)$ in the SSAm10 simulation, illustrating the fact that aerosols can exert a warming or a cooling of the "surface-atmosphere" system depending on

Table 3a. SW+LW DJF Radiative Forcing in W/m² Over the Four Subdomains ${ }^{\mathrm{a}}$

\begin{tabular}{|c|c|c|c|c|c|c|c|c|c|c|c|c|c|c|c|c|}
\hline & \multicolumn{16}{|c|}{ Radiative Forcing $\left(\mathrm{W} / \mathrm{m}^{2}\right)$} \\
\hline & \multicolumn{4}{|c|}{$\begin{array}{c}\text { Land: Sahel } \\
\left(5^{\circ} \mathrm{N} ; 13^{\circ} \mathrm{N}\right)\left(10^{\circ} \mathrm{W} ; 20^{\circ} \mathrm{E}\right)\end{array}$} & \multicolumn{4}{|c|}{$\begin{array}{c}\text { Ocean: Gulf } \\
\left(9^{\circ} \mathrm{S} ; 5^{\circ} \mathrm{N}\right)\left(20^{\circ} \mathrm{W} ; 8^{\circ} \mathrm{E}\right)\end{array}$} & \multicolumn{4}{|c|}{$\begin{array}{c}\text { Land: Desert } \\
\left(15^{\circ} \mathrm{N} ; 28^{\circ} \mathrm{N}\right)\left(13^{\circ} \mathrm{W} ; 30^{\circ} \mathrm{E}\right)\end{array}$} & \multicolumn{4}{|c|}{$\begin{array}{c}\text { Ocean: Atlantic } \\
\left(5^{\circ} \mathrm{S} ; 25^{\circ} \mathrm{N}\right)\left(27^{\circ} \mathrm{W} ; 18^{\circ} \mathrm{W}\right)\end{array}$} \\
\hline & SRF & ATM & TOA & SSA & SRF & ATM & TOA & SSA & SRF & ATM & TOA & SSA & SRF & ATM & TOA & SSA \\
\hline & 28.2 & 24. & -3 & 0 & 245 & 19.8 & -4 & 0 . & 7 & & & & -1 & & & 08 \\
\hline US & -5.58 & 2.61 & -2.97 & 0.9 & -2 . & 1. & -1.41 & 0.941 & -6.0 & 4.8 & -1.10 & 0.917 & -5.78 & 2.1 & -3.62 & 0.938 \\
\hline BCOCex & -23.04 & 21.99 & -1.06 & 0.783 & -21.97 & 18.88 & -3.10 & 0.796 & -4.81 & 5.75 & 0.94 & 0.78 & -11.02 & 9.44 & -1.57 & 0.79 \\
\hline
\end{tabular}

\footnotetext{
${ }^{a}$ See Figure 7c. The simulation BCOCex includes only carbonaceous aerosols. The simulation DUSTex includes only dust aerosols. The SSA values are
} reported for the $500 \mathrm{~nm}$ wavelength. 
Table 3b. SW+LW DJF Radiative Forcing Efficiency in $\mathrm{W} / \mathrm{m}^{2} / \mathrm{AOT}_{500 \mathrm{~nm}}$ Over the Four Subdomains ${ }^{\mathrm{a}}$

\begin{tabular}{|c|c|c|c|c|c|c|c|c|c|c|c|c|c|c|c|c|}
\hline & \multicolumn{16}{|c|}{ Radiative Forcing Efficiency (W/m²/AOT) } \\
\hline & \multicolumn{4}{|c|}{$\begin{array}{l}\text { Land: Sahel } \\
\left(5^{\circ} \mathrm{N} ; 13^{\circ} \mathrm{N}\right)\left(10^{\circ} \mathrm{W} ; 20^{\circ} \mathrm{E}\right) \\
\end{array}$} & \multicolumn{4}{|c|}{$\begin{array}{c}\text { Ocean: Gulf } \\
\left(9^{\circ} \mathrm{S} ; 5^{\circ} \mathrm{N}\right)\left(20^{\circ} \mathrm{W} ; 8^{\circ} \mathrm{E}\right) \\
\end{array}$} & \multicolumn{4}{|c|}{$\begin{array}{c}\text { Land: Desert } \\
\left(15^{\circ} \mathrm{N} ; 28^{\circ} \mathrm{N}\right)\left(13^{\circ} \mathrm{W} ; 30^{\circ} \mathrm{E}\right)\end{array}$} & \multicolumn{4}{|c|}{$\begin{array}{c}\text { Ocean: Atlantic } \\
\left(5^{\circ} \mathrm{S} ; 25^{\circ} \mathrm{N}\right)\left(27^{\circ} \mathrm{W} ; 18^{\circ} \mathrm{W}\right)\end{array}$} \\
\hline & SRF & ATM & TOA & SSA & $\mathrm{SRF}$ & ATM & TOA & SSA & $\mathrm{SRF}$ & ATM & TOA & SSA & SRF & ATM & TOA & SSA \\
\hline REF & -60.99 & 52.64 & -8.346 & 0.834 & -76.683 & 60.243 & -14.439 & 0.822 & -38.340 & 37.608 & -0.732 & 0.882 & -64.848 & 44.663 & -20.185 & 0.870 \\
\hline DUSTex & -45.20 & 21.11 & -24.09 & 0.939 & -59.24 & 25.94 & -33.3 & 0.941 & -30.82 & 25.15 & -5.68 & 0.917 & -53.1 & 19.77 & -33.33 & 0.938 \\
\hline BCOCex & -70.99 & 67.73 & -3.26 & 0.783 & -80.11 & 68.82 & -11.29 & 0.796 & -67.2 & 80.42 & 13.21 & 0.78 & -79.25 & 67.93 & -11.32 & 0.79 \\
\hline
\end{tabular}

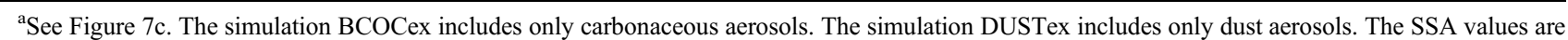
reported for the $500 \mathrm{~nm}$ wavelength.

their absorption efficiency. Over the gulf of Guinea, where biomass burning aerosols dominate, the SRF and ATM DRF efficiency changes are about $\pm 11.14 \mathrm{~W} \mathrm{~m} \mathrm{~m}^{-2} / \mathrm{AOT}_{500 \mathrm{~nm}}$ (uncertainty of $\sim 14 \%$ ) and $\pm 17.0 \mathrm{~W} \mathrm{~m} \mathrm{~m}^{-2} / \mathrm{AOT}_{500 \mathrm{~nm}}$ (uncertainty of $\sim 28 \%$ ) for BB SSA varying from $\pm 10 \%$.

\subsection{Atmospheric Heating Rate due to Aerosols}

[57] As mentioned in section 3.2, one of the most important points of our study concerns the very strong absorption of radiation by aerosols observed in the West African region and which leads to significant local diabatic heating. In order to assess whether the heating due to the simulated aerosol loading is realistic, we compare the aerosol SW heating rate $(\mathrm{K} / \mathrm{d})$ diagnosed in RegCM3 with offline single-column radiative transfer calculations performed using the Edwards and Slingo [1996] model (ES96 hereafter) to estimate the corresponding radiative heating rates following the same method as Johnson et al. [2008a]. Aircraft measurements made by the UK Facility for Airborne Atmospheric Measurements (FAAM) BAe-146 aircraft during DABEX provided input data for aerosol extinction profiles, and thermal and humidity profiles to the ES96 model. The aerosol extinction was derived from a nephelometer and particle soot absorption photometer and was segregated into dust and $\mathrm{BB}$ components following Johnson et al. [2008a]. The aerosol profiles measured during this period (mid-January to mid-February 2006) are assumed to be representative of the typical aerosol background during the dry season at Niamey. All calculations are performed for cloud-free conditions. The RegCM3 extinction profiles are taken from the simulation outputs at the closest grid point to the Niamey location. It is important to keep in mind that the ES96 calculations and RegCM3 calculations assume different aerosol extinction profiles. The accuracy of the RegCM3 heating rate profiles would depend on the accurate simulation of a realistic aerosol extinction profile. The aerosol SW heating rate in RegCM3 is computed by saving the difference in the net SW flux between calculations with aerosol and without aerosol at each call of the $\mathrm{RegCM} 3$ radiative transfer routines. The radiative fluxes difference is then converted into the SW heating rate. The method implies that the same atmospheric thermodynamic state is kept during the computation in order to avoid feedback from the atmosphere due to aerosol radiative effects.

[58] Figure 9 presents the comparisons between RegCM3 SW heating rate (plain line) and heating rate calculations from the ES96 radiative transfer model (dashed line) are represented. Figure 9 (left) shows the diurnally averaged heating rates between December 2005 and January 2006, while Figure 9 (right) shows the instantaneous value of SW heating rate at noon averaged over the same period. The DABEX and RegCM3 (December-January averages) extinction profile (at $550 \mathrm{~nm}$ and $530 \mathrm{~nm}$, respectively) are also overlaid. The simulated aerosol extinction profile compares reasonably with the DABEX observations. As discussed in section 3.2, the model simulates an elevated layer dominated by carbonaceous aerosols around 850-600 hPa and a lower layer between the surface and $800 \mathrm{hPa}$ dominated by mineral dust aerosols. However, as discussed previously, the dust aerosol extinction is strongly underestimated in the lowest part of the atmosphere at Niamey.

[59] In Figure 9 (left), aerosol SW heating rate profiles from both the ES96 calculations and RegCM3 show a maximum in the burning biomass layer. This results from the lower SSA of biomass burning aerosols that absorb solar radiation more efficiently than scattering dust aerosols. The ES96 SW heating rate peaks around $700 \mathrm{hPa}$ and reaches diurnal average value of $0.4 \mathrm{~K} / \mathrm{d}$ and $1.2 \mathrm{~K} / \mathrm{d}$ for the noon profile. The SW heating rates simulated by RegCM3 show a similar pattern, with a peak around $700 \mathrm{hPa}$, but the magnitude of SW heating is underestimated compared to the

Table 4a. SW+LW DJF Radiative Forcing in W/m² Over the Four Subdomains for the REF Simulation and Simulations SSAm10 and SSAp $10^{\mathrm{a}}$

\begin{tabular}{|c|c|c|c|c|c|c|c|c|c|c|c|c|c|c|c|c|}
\hline & \multicolumn{16}{|c|}{ Radiative Forcing $\left(\mathrm{W} / \mathrm{m}^{2}\right)$} \\
\hline & \multicolumn{4}{|c|}{$\begin{array}{c}\text { Land: Sahel } \\
\left(5^{\circ} \mathrm{N} ; 13^{\circ} \mathrm{N}\right)\left(10^{\circ} \mathrm{W} ; 20^{\circ} \mathrm{E}\right)\end{array}$} & \multicolumn{4}{|c|}{$\begin{array}{c}\text { Ocean: Gulf } \\
\left(9^{\circ} \mathrm{S} ; 5^{\circ} \mathrm{N}\right)\left(20^{\circ} \mathrm{W} ; 8^{\circ} \mathrm{E}\right)\end{array}$} & \multicolumn{4}{|c|}{$\begin{array}{c}\text { Land: Desert } \\
\left(15^{\circ} \mathrm{N} ; 28^{\circ} \mathrm{N}\right)\left(13^{\circ} \mathrm{W} ; 30^{\circ} \mathrm{E}\right)\end{array}$} & \multicolumn{4}{|c|}{$\begin{array}{c}\text { Ocean: Atlantic } \\
\left(5^{\circ} \mathrm{S} ; 25^{\circ} \mathrm{N}\right)\left(27^{\circ} \mathrm{W} ; 18^{\circ} \mathrm{W}\right)\end{array}$} \\
\hline & SRF & ATM & TOA & SSA & SRF & ATM & TOA & SSA & SRF & ATM & TOA & SSA & SRF & ATM & TOA & SSA \\
\hline & 28.27 & 2 & J. & 834 & -24.597 & 19.841 & -4.756 & 0.822 & -10.417 & & -0 . & 0.882 & & & 81 & 0.870 \\
\hline $\mathrm{m} 10$ & -32.30 & 30.942 & -1.357 & 0.780 & -28.74 & 26.12 & -2.62 & 0.756 & -11.284 & 11.908 & 0.624 & 0. & -18.66 & 14.558 & -4.104 & 0.832 \\
\hline SAp10 & -25.016 & 19.16 & -5.855 & 0.879 & -21.40 & 14.93 & -6.47 & 0.875 & -9.73 & 8.91 & -0.82 & 0.898 & -15.08 & 9.03 & -6.05 & 0.900 \\
\hline
\end{tabular}

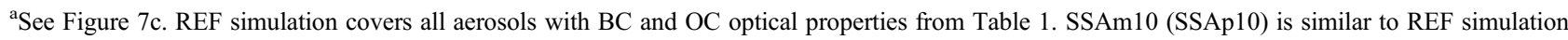
except that the $\mathrm{BC}$ and $\mathrm{OC}$ tracers SSA have been lowered (increased) by $10 \%$. 
Table 4b. SW+LW DJF Radiative Forcing Efficiency in $\mathrm{W} / \mathrm{m}^{2} / \mathrm{AOT}_{500} \mathrm{~nm}$ Over the Four Subdomains for the REF Simulation and Simulations SSAm10 and SSAp10

\begin{tabular}{|c|c|c|c|c|c|c|c|c|c|c|c|c|c|c|c|c|}
\hline & \multicolumn{16}{|c|}{ Radiative Forcing Efficiency $\left(\mathrm{W} / \mathrm{m}^{2} / \mathrm{AOT}\right)$} \\
\hline & \multicolumn{4}{|c|}{$\begin{array}{l}\text { Land: Sahel } \\
\left(5^{\circ} \mathrm{N} ; 13^{\circ} \mathrm{N}\right)\left(10^{\circ} \mathrm{W} ; 20^{\circ} \mathrm{E}\right) \\
\end{array}$} & \multicolumn{4}{|c|}{$\begin{array}{c}\text { Ocean: Gulf } \\
\left(9^{\circ} \mathrm{S} ; 5^{\circ} \mathrm{N}\right)\left(20^{\circ} \mathrm{W} ; 8^{\circ} \mathrm{E}\right) \\
\end{array}$} & \multicolumn{4}{|c|}{$\begin{array}{c}\text { Land: Desert } \\
\left(15^{\circ} \mathrm{N} ; 28^{\circ} \mathrm{N}\right)\left(13^{\circ} \mathrm{W} ; 30^{\circ} \mathrm{E}\right) \\
\end{array}$} & \multicolumn{4}{|c|}{$\begin{array}{c}\text { Ocean: Atlantic } \\
\left(5^{\circ} \mathrm{S} ; 25^{\circ} \mathrm{N}\right)\left(27^{\circ} \mathrm{W} ; 18^{\circ} \mathrm{W}\right) \\
\end{array}$} \\
\hline & SRF & ATM & TOA & SSA & SRF & ATM & TOA & SSA & SRF & ATM & TOA & SSA & SRF & ATM & TOA & SSA \\
\hline & -60.99 & 52.64 & -8.34 & 0.834 & -76.683 & 60.243 & -1 & 0.822 & -38 & 37 & -0 & 0. & 8 & 44 & & 0.8 \\
\hline SSAm 10 & -69.67 & 66.75 & -2.927 & 0.780 & -87.26 & 79.29 & -7.965 & 0.756 & -41.533 & 43.829 & 2.296 & 0.8 & -72.70 & 56.71 & -15.99 & 0.832 \\
\hline SSAp10 & -53.964 & 41.33 & -12.63 & 0.879 & -64.98 & 45.33 & -19.65 & 0.875 & -35.80 & 32.78 & -3.01 & 0.898 & -58.746 & 35.19 & -23.56 & 0.900 \\
\hline
\end{tabular}

${ }^{a}$ See Figure 7c. REF simulation covers all aerosols with BC and OC optical properties from Table 1. SSAm10 (SSAp10) is similar to REF simulation except that the $\mathrm{BC}$ and $\mathrm{OC}$ tracers SSA have been lowered (increased) by $10 \%$.

ES96 computation. This is directly a result of the underestimation of the extinction by smoke aerosol at this location in the simulation (as previously discussed). In addition, the extinction and the SW heating rate (diurnally averaged) fields averaged between 600 and $850 \mathrm{hPa}$ for the whole domain are shown in Figures 10a and 10b, corresponding to the layer where absorbing carbonaceous aerosols dominate the aerosol loading. The average aerosol extinction over the Sahel/ocean range between 0.05 and $0.12 \mathrm{~km}^{-1}$ and the associated aerosol heating rates are approximately $0.3-0.6 \mathrm{~K} / \mathrm{d}$. These values are consistent with radiative transfer calculations based on the DABEX mean aerosol profiles at Niamey.

[60] Above $600 \mathrm{hPa}$, the DABEX extinction profile is assumed to be zero whereas in RegCM3, low extinction values remain. Consequently, in the free troposphere, the RegCM3 aerosol heating rate is nonzero and still significant compared to the maximum value at $700 \mathrm{hPa}$. Similarly, in the lowest troposphere, the $\mathrm{BB}$ aerosol extinction is higher in RegCM3 than in the DABEX profile. Despite the large underestimation of dust aerosols close to the surface, the RegCM3 heating rate is slightly overestimated compared to the heating rate from the ES96 calculations as a result of the enhanced absorption of biomass burning aerosols, of which there are greater concentrations in RegCM3. The relative contribution of $\mathrm{BB}$ aerosols to the total aerosol extinction is shown in Figure 10c.

\section{Summary}

[61] This study estimates the direct radiative forcing (DRF) of aerosols over the West African (WA) region which is dominated by mineral dust and biomass burning
$\{2 \mathrm{E} ; 13.5 \mathrm{~N}\}$ DEC-JAN diurnal avg Extinction $(\mathrm{km}-1)$

$\begin{array}{lllllll}0.00 & 0.03 & 0.06 & 0.09 & 0.12 & 0.15 & 0.18\end{array}$

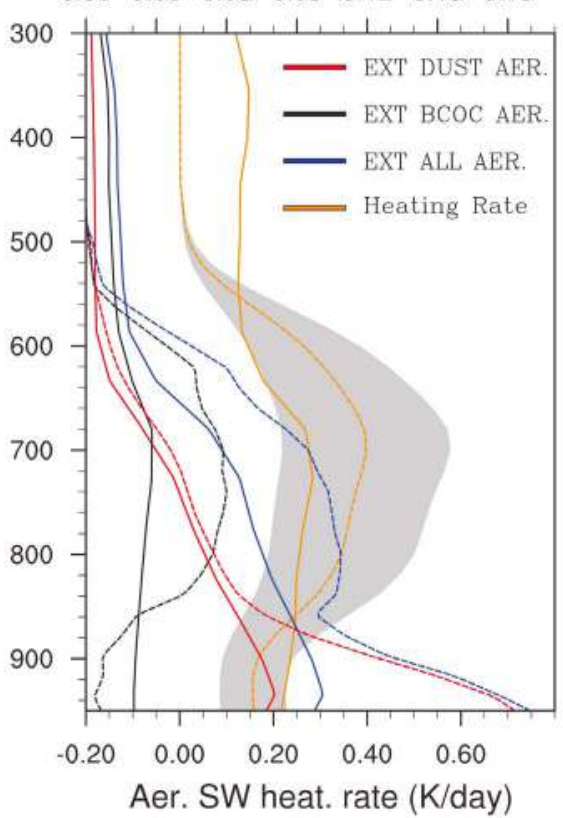

\{2E;13.5N\} DEC-JAN noon avg Extinction (km-1)

$\begin{array}{lllllll}0.00 & 0.03 & 0.06 & 0.09 & 0.12 & 0.15 & 0.18\end{array}$

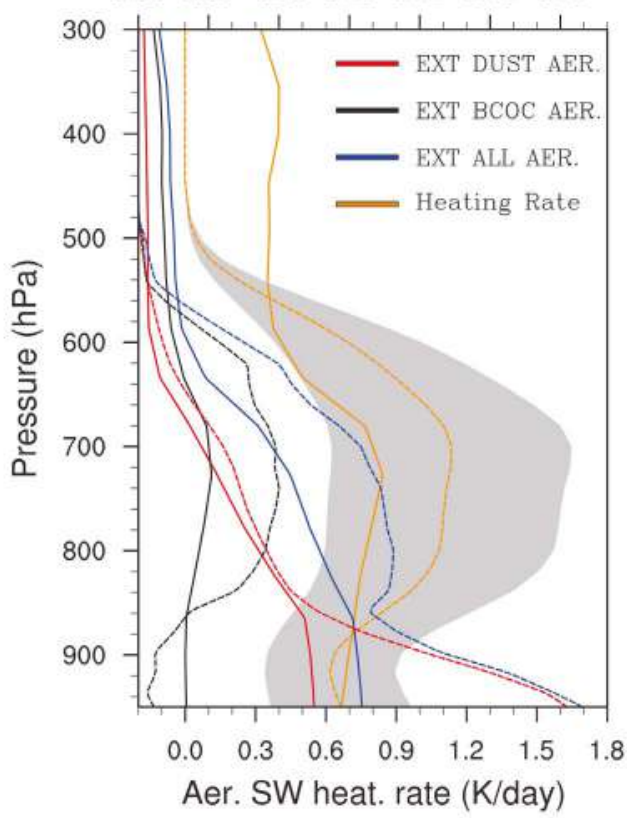

Figure 9. Heating rate associated to aerosols in $\mathrm{K} / \mathrm{d}$ (yellow) and aerosols extinction profiles in $\mathrm{km}^{-1}$ (left) diurnally averaged between December 2005 and January 2006 and (right) noon averaged between December 2005 and January 2006 at Niamey location. Dotted lines represent ES96 calculations (see text) whereas solid lines represent RegCM3 calculations. Grey shaded area corresponds to the estimated uncertainty of $50 \%$ associated to the ES96 aerosol heating rate profile. 

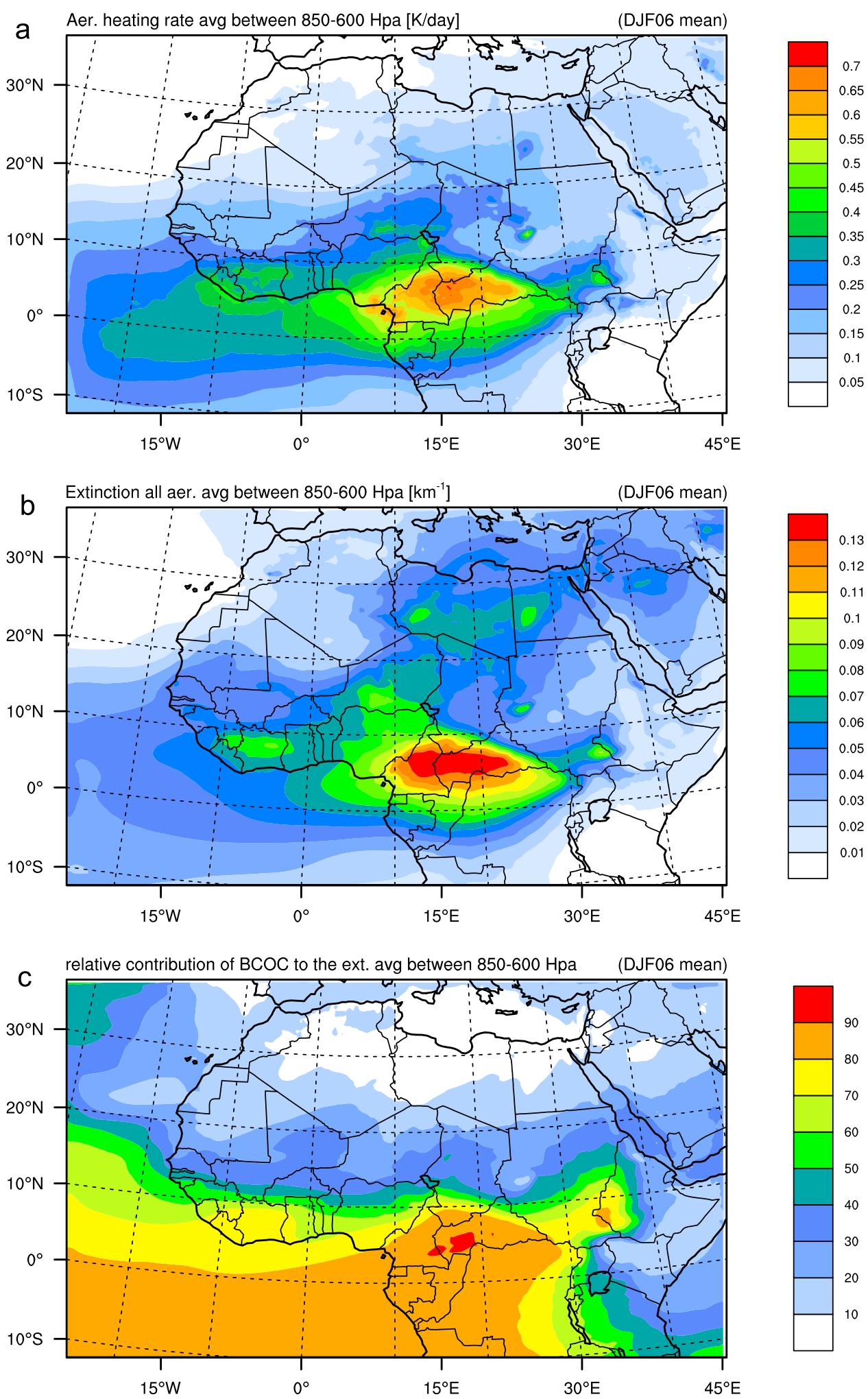

Figure 10. Averaged between 600 and $850 \mathrm{hPa}$ of (a) aerosol heating rate, (b) aerosol extinction, and (c) relative contribution of $\mathrm{BB}$ aerosol to total aerosol extinction averaged for DJF.

emissions. Although aerosols have an important influence on the radiative energy budget in WA the DRF remains uncertain. The goal of this study was to reduce such uncertainties. We performed RegCM3 simulations over
West Africa for the dry season of October 2005 to April 2006. We focused our attention on the ability of the model to simulate the aerosol loading, their optical properties, vertical distribution and the regional distribution of aerosols 
and aerosol DRF. The simulations included the major aerosol species: smoke aerosols from biomass burning, biofuel combustion and domestic burning and mineral dust resulting from the erosion of arid lands. Data from recent field campaigns (DABEX, AMMA SOP-0, and DODO) have been used to evaluate and constrain our aerosol simulations.

[62] The modeled SSA was shown to vary during the simulated period, reaching minimum values during December-January as consistent with AERONET observations. During December-January, RegCM3 SSA values dropped to $0.81-0.83$ at $440 \mathrm{~nm}$ and $0.80-0.85$ at $675 \mathrm{~nm}$ when absorbing aerosols from biomass burning dominated the aerosol mixture. During March and April, mineral dust dominated and SSA increased to reach mean values of $0.90-0.92$ at $440 \mathrm{~nm}$ and $0.94-0.96$ at $675 \mathrm{~nm}$.

[63] The modeled Aerosol Optical Thickness (AOT) was generally in good agreement with AERONET measurements obtained in the Sahelian belt. However, during strong dust events, the model dust scheme showed weakness in estimating the aerosol loading. Comparison of modeled AOT with remote sensing retrievals showed a major disagreement in central Africa, indicating both a possible overestimation of biomass burning emissions or inaccurate underestimation of AOT in satellite retrievals due to cloud screening. Satellite observations showed a maximum of AOT ( 0.7-0.8 at $550 \mathrm{~nm}$ ) close to the region of Lagos but comparison with the model suggest a possible underestimation of $\mathrm{FF}$ and $\mathrm{BF}$ emissions in the anthropogenic inventories. Further simulations with updated anthropogenic inventories are required in the future to address this discrepancy.

[64] Comparisons with LIDAR measurements and aircraft measurements from DABEX obtained at Niamey and M'bour show the following: (1) The observed layering (BB aerosol above dust) was well reproduced by RegCM3. (2) The dust loading at low altitudes was underestimated away from model's preferential dust sources, in particular under $\sim 10^{\circ} \mathrm{N}-15^{\circ} \mathrm{N}$ corresponding to the location of the ITF. In contrast the model tends to overestimate dust emissions close to the model's dust source.

[65] The clear sky direct radiative forcing (DRF) of aerosols was estimated at TOA and SRF in both the SW and LW spectral region. Over dark surfaces, the TOA DRF was strongly negative, with values between -5.25 and $-4.0 \mathrm{~W} / \mathrm{m}^{2}$. Over bright surfaces such as desert, the TOA DRF was close to zero $\left(-0.15 \mathrm{~W} / \mathrm{m}^{2}\right)$, illustrating the absorbing nature of the aerosol mixing. The large difference between SRF and TOA DRF indicated that absorption of SW radiation was important for radiative transfer in the atmospheric column. Consequently special attention was made to evaluate the simulated SW heating rate induced by the aerosol.

[66] The SW heating rates associated with the aerosols were diagnosed by RegCM3 and compared with single column radiative transfer calculations based on DABEX measurements for the location of Niamey. The results of the single column radiative transfer calculations show a maximum heating rate in the layer dominated by $\mathrm{BB}$ aerosols (typically between 850 and $600 \mathrm{hPa}$ ). Diurnal average and noon average SW heating rates reached moderate-high values of $0.40 \mathrm{~K} / \mathrm{d}$ and $1.2 \mathrm{~K} / \mathrm{d}$, respectively, for December-January conditions. RegCM3 calculations showed a peak in the heating rate in the same altitude range as the single column
DABEX results. This was consistent with a reasonable vertical distribution of $\mathrm{BB}$ aerosols. However, the model strongly underestimated the magnitude of the heating rates ( $\sim 80 \%$ lower in the BB layers). This was due to the underestimation of the total extinction (and hence absorption) by smoke aerosol at this location in the RegCM3 simulation. At a more regional scale, in areas where the smoke extinction profiles were comparable to the DABEX measurements at Niamey, the RegCM3 SW heating rates agreed well with offline radiative transfer calculations. This agreement gives a certain confidence in the modeled aerosol optical properties, which are very important for the climatic impact of smoke aerosol. More systematic comparisons of RegCM3 estimations with SW heating rates retrieved from the CALIOP LIDAR aboard CALIPSO spacecraft [Lemaittre et al., 2010] may provide a better validation approach by allowing a more comprehensive regional assessment.

[67] The study concludes that RegCM3 may benefit from new information regarding dust refractive indices obtained during AMMA [McConnell et al., 2010]. Future work is planned to incorporate and test this information in the RegCM3 model. Improvements to dust LW optical properties may enable a better assessment of the LW direct radiative forcings of dust particles, which remain poorly estimated. Another issue flagged in this study is that the parameterization of Alfaro and Gomes [2001] used to simulate the size distributed dust emission flux in RegCM3 is not well constrained regionally and may lead to the overestimation of the fine mode dust emission. Improvements to the scheme following Crumeyrolle et al. [2010] should be considered in future research. Finally, further research will explore the possible mixing between $\mathrm{BB}$ and mineral dust aerosols over the West African region.

[68] The following step to the work presented in this paper will be to extend the period of simulation in a new study focusing on the impact of mixed aerosols (BB and mineral dust) on the WA regional climate. This work is ongoing and should complement previous studies performed with the same model but with dust only [Solmon et al., 2008].

[69] Acknowledgments. On the basis of a French initiative, AMMA was built by an international scientific group and is currently funded by a large number of agencies, especially from France, UK, United States, and Africa. It has been the beneficiary of a major financial contribution from the European Community's Sixth Framework Research Programme. AMMA has been endorsed by IGBP (IGAC, ILEAPS) and WCRP (GEWEX, CLIVAR). Detailed information on scientific coordination and funding is available on the AMMA International Web site (http://www.amma-international.org). The authors would like also to thank the PIs of AERONET sites of Agoufou, Banizoumbou, Capo Verde, Djougou, Maine Soroa, Cinzana, and Ilorin for the data collection. We would like also to thank Sally McFarlane for providing the aerosol extinction profiles at Niamey. The authors thank Laboratoire d'Optique Atmospherique for operating the LIDAR system in M'Bour. FAAM is jointly funded by the Met Office and the Natural Environment Research Council. MODIS and MISR data used in this study were produced with the Giovanni online data system, developed and maintained by the NASA GES DISC. PARASOL data were provided by ICARE system developed and maintained by the University of Lille. MOPITT data were obtained from the NASA Langley Research Center Atmospheric Science Data Center.

\section{References}

Abel, S. J., J. M. Haywood, E. J. Highwood, J. Li, and P. R. Buseck (2003), Evolution of biomass burning aerosol properties from an agricultural fire in southern Africa, Geophys. Res. Lett., 30(15), 1783, doi:10.1029/ 2003 GL017342. 
Alfaro, S. C., and L. Gomes (2001), Modeling mineral aerosol production by wind erosion: Emission intensities and aerosol size distributions in source areas, J. Geophys. Res., 106(D16), 18,075-18,084, doi:10.1029/ 2000JD900339.

Andreae, M. O., and A. Gelencser (2006), Black carbon or brown carbon? The nature of light-absorbing carbonaceous aerosols, Atmos. Chem. Phys., 6(10), 3131-3148, doi:10.5194/acp-6-3131-2006.

Andreae, M. O., C. D. Jones, and P. M. Cox (2005), Strong present-day aerosol cooling implies a hot future, Nature, 435(7046), 1187-1190, doi:10.1038/nature03671.

Anyamba, A. (2003), Seasonal to interannual variability of vegetation and fires at SAFARI 2000 sites inferred from advanced very high resolution radiometer time series data, J. Geophys. Res., 108(D13), 8507 doi:10.1029/2002JD002464.

Assamoi, E., and C. Liousse (2010), A new inventory for two-wheel vehicle emissions in West Africa for 2002, Atmos. Environ., 44(32), 3985-3996, doi:10.1016/j.atmosenv.2010.06.048.

Bond, T. C., and R. W. Bergstrom (2006), Light absorption by carbonaceous particles: An investigative review, Aerosol Sci. Technol., 40(1), 27-67, doi:10.1080/02786820500421521.

Briegleb, B. P. (1992), Delta-Eddington approximation for solar radiation in the NCAR Community Climate Model, J. Geophys. Res., 97(D7), 7603-7612, doi:10.1029/92JD00291.

Cavazos, C., M. C. Todd, and K. Schepanski (2009), Numerical model simulation of the Saharan dust event of 6-11 march 2006 using the regional climate model version 3(RegCM3), J. Geophys. Res., 114, D12109, doi:10.1029/2008JD011078.

Chakrabarty, R. K., H. Moosmüller, L.-W. A. Chen, K. Lewis, W. P. Arnott, C. Mazzolen, M. Dubey, C. E. Wold, W. M. Hao, and S. M. Kreidenweis (2010), Brown carbon in tar balls from smoldering biomass combustion, Atmos. Chem. Phys. Discuss., 10(3), 6279-6300, doi:10.5194/acpd-106279-2010.

Charlson, R. J., S. E. Schwartz, J. M. Hales, R. D. Cess, J. A. Coakley, J. E. Hansen, and D. J. Hofmann (1992), Climate forcing by anthropogenic aerosols, Science, 255(5043), 423-430, doi:10.1126/science. 255.5043.423.

Cooke, W. F., C. Liousse, H. Cachier, and J. Feichter (1999), Construction of a $1^{\circ} \times 1^{\circ}$ fossil fuel emission data set for carbonaceous aerosol and implementation and radiative impact in the ECHAM4 model, J. Geophys. Res., 104(D18), doi:10.1029/1999JD900187.

Crumeyrolle, S., P. Tulet, L. Garcia-Carreras, C. Flamant, D. J. Parker, A. Matsuki, A. Schwarzenboeck, P. Formenti, and L. Gomes (2010), Transport of dust particles from the Bodélé region to the monsoon layer: AMMA case study of the 9-14 June 2006 period, Atmos., Chem. Phys. Discuss., 10(2), 5051-5090, doi:10.5194/acpd-10-5051-2010.

Deeter, M. N., et al. (2003), Operational carbon monoxide retrieval algorithm and selected results for the MOPITT instrument, J. Geophys. Res., 108(D14), 4399, doi:10.1029/2002JD003186.

Derimian, Y., J.-F. Léon, O. Dubovik, I. Chiapello, D. Tanré, A. Sinyuk, F. Auriol, T. Podvin, G. Brogniez, and B. Holben (2008a), Radiative properties of aerosol mixture observed during the dry season 2006 over M'Bour, Senegal (African Monsoon Multidisciplinary Analysis campaign), J. Geophys. Res., 113, D00C09, doi:10.1029/2008JD009904.

Derimian, Y., A. Karnieli, Y. J. Kaufman, M. O. Andreae, T. W. Andreae, O. Dubovik, W. Maenhaut, and I. Koren (2008b), The role of iron and black carbon in aerosol light absorption, Atmos. Chem. Phys., 8(13), 3623-3637, doi:10.5194/acp-8-3623-2008.

Deuzé, J.-L., et al. (2001), Remote sensing of aerosols over land surfaces from POLDER-ADEOS-1 polarized measurements, J. Geophys. Res., 106(D5), 4913-4926, doi:10.1029/2000JD900364.

Dickinson, R. E., A. Henderson-Sellers, and P. J. Kennedy (1993), Biosphere-atmosphere transfer scheme (BATS) version 1e as coupled to the NCAR community climate model, Tech. Rep. NCAR/TN-387+ STR, NCAR, Boulder, Colo.

Dinar, E., A. A. Riziq, C. Spindler, C. Erlick, G. Kiss, and Y. Rudich (2008), The complex refractive index of atmospheric and model humic-like substances (HULIS) retrieved by a cavity ring down aerosol spectrometer (CRD-AS), Faraday Discuss., 137, 279-295, doi:10.1039/ b703111d.

Diner, D. J., et al. (1998), Multi-angle Imaging SpectroRadiometer (MISR) instrument description and experiment overview, IEEE Trans. Geosci. Remote Sens., 36(4), 1072-1087, doi:10.1109/36.700992.

Dubovik, O., A. Smirnov, B. N. Holben, M. D. King, Y. J. Kaufman, T. F. Eck, and I. Slutsker (2000), Accuracy assessments of aerosol optical properties retrieved from aerosol robotic network (AERONET) Sun and sky radiance measurements, J. Geophys. Res., 105(D8), 9791-9806, doi:10.1029/2000JD900040.

Dubovik, O., B. Holben, T. F. Eck, A. Smirnov, Y. J. Kaufman, M. D. King, D. Tanré, and I. Slutsker (2002), Variability of absorption and opti- cal properties of key aerosol types observed in worldwide locations, J. Atmos. Sci., 59(3), 590-608, doi:10.1175/1520-0469(2002) 059<0590:VOAAOP $>2.0 . \mathrm{CO} ; 2$.

Dufresne, J., C. Gautier, P. Ricchiazzi, and Y. Fouquart (2002), Longwave scattering effects of mineral aerosols, J. Atmos. Sci., 59(12), 1959-1966, doi:10.1175/1520-0469(2002)059<1959:LSEOMA>2.0.CO;2.

Eck, T. F., B. N. Holben, J. S. Reid, O. Dubovik, A. Smirnov, N. T. O’Neill, I. Slutsker, and S. Kinne (1999), Wavelength dependence of the optical depth of biomass burning, urban, and desert dust aerosols, J. Geophys. Res., 104(D24), 31,333-31,349, doi:10.1029/1999JD900923.

Edwards, J. M., and A. Slingo (1996), Studies with a flexible new radiation code. I: Choosing a configuration for a large-scale model, $Q . J . R$ Meteorol. Soc., 122(531), 689-719, doi:10.1002/qj.49712253107.

Forster, P., et al. (2007), Changes in atmospheric constituents and in radiative forcing, in Climate Change 2007: The Physical Science Basis. Contribution of Working Group I to the Fourth Assessment Report of the Intergovernmental Panel on Climate Change, edited by S. Solomon et al., pp. 129-234, Cambridge Univ. Press, Cambridge, U. K.

Giorgi, F. (1989), Two-dimensional simulations of possible mesoscale effects of nuclear war fires 1. Model description, J. Geophys. Res. 94(D1), 1127-1144, doi:10.1029/JD094iD01p01127.

Giorgi, F., and W. L. Chameides (1986), Rainout lifetimes of highly soluble aerosols and gases as inferred from simulations with a general circulation model, J. Geophys. Res., 91(D13), 14,367-14,376, doi:10.1029/ JD091iD13p14367.

Giorgi, F., and L. O. Mearns (1999), Introduction to special section: Regional climate modeling revisited, J. Geophys. Res., 104(D6), 6335-6352. doi:10.1029/98JD02072.

Giorgi, F., R. Francisco, and J. S. Pal (2003), Effects of a subgrid-scale topography and land use scheme on the simulation of surface climate and hydrology. Part I: Effects of temperature and water vapor disaggregation, J. Hydrometeorol., 4, 317-333, doi:10.1175/1525-7541(2003) 4<317:EOASTA $>2.0 . \mathrm{CO} ; 2$.

Grell, G. A. (1993), Prognostic evaluation of assumptions used by cumulus parameterizations, Mon. Weather Rev., 121, 764-787, doi:10.1175/15200493(1993) $121<0764$ :PEOAUB $>2.0$.CO;2.

Grini, A., P. Tulet, and L. Gomes (2006), Dusty weather forecasts using the MesoNH mesoscale atmospheric model, J. Geophys. Res., 111, D19205, doi:10.1029/2005JD007007.

Haywood, J. M., S. R. Osborne, P. N. Francis, A. Keil, P. Formenti, M. O. Andreae, and P. H. Kaye (2003), The mean physical and optical properties of regional haze dominated by biomass burning aerosol measured from the C-130 aircraft during SAFARI 2000, J. Geophys. Res., 108(D13), 8473, doi:10.1029/2002JD002226.

Haywood, J. M., et al. (2008), Overview of the Dust and Biomass-Burning Experiment and African Monsoon Multidisciplinary Analysis Special Observing Period-0, J. Geophys. Res., 113, D00C17, doi:10.1029/ 2008JD010077.

Heese, B., and M. Wiegner (2008), Vertical aerosol profiles from Raman polarization lidar observations during the dry season AMMA field campaign, J. Geophys. Res., 113, D00C11, doi:10.1029/2007JD009487.

Heinold, B., J. Helmert, O. Hellmuth, R. Wolke, A. Ansmann, B. Marticorena B. Laurent, and I. Tegen (2007), Regional modeling of Saharan dust events using LM-MUSCAT: Model description and case studies, J. Geophys. Res. 112, D11204, doi:10.1029/2006JD007443.

Herman, M., J. Deuzé, A. Marchand, B. Roger, and P. Lallart (2005), Aerosol remote sensing from POLDER/ADEOS over the ocean: Improved retrieval using a nonspherical particle model, J. Geophys. Res., 110 D10S02, doi:10.1029/2004JD004798.

Holben, B., et al. (1998), AERONET-A federated instrument network and data archive for aerosol characterization, Remote Sens. Environ., 66(1), 1-16, doi:10.1016/S0034-4257(98)00031-5.

Holtslag, A. A. M., E. I. F. de Bruijin, and H. L. Pan (1990), A high resolution air mass transformation model for short-range weather forecasting, Mon. Weather Rev., 118, 1561-1575, doi:10.1175/1520-0493 (1990) $118<1561$ :AHRAMT>2.0.CO;2.

Hungershoefer, K., K. Zeromskiene, Y. Iinuma, G. Helas, J. Trentmann, T. Trautmann, R. S. Parmar, A. Wiedensohler, M. O. Andreae, and O. Schmid (2008), Modelling the optical properties of fresh biomass burning aerosol produced in a smoke chamber: Results from the EFEU campaign, Atmos. Chem. Phys., 8(13), 3427-3439, doi:10.5194/acp-83427-2008.

Johnson, B. T., K. P. Shine, and P. M. Forster (2004), The semidirect aerosol effect: Impact of absorbing aerosols on marine stratocumulus, $Q$. J. R Meteorol. Soc., 130(599), 1407-1422, doi:10.1256/qj.03.61.

Johnson, B., B. Heese, S. McFarlane, P. Chazette, A. Jones, and N. Bellouin (2008a), Vertical distribution and radiative effects of mineral dust and biomass burning aerosol over West Africa during DABEX, J. Geophys. Res., 113, D00C12, doi:10.1029/2008JD009848. 
Johnson, B., S. Osborne, J. Haywood, and M. Harrison (2008b), Aircraft measurements of biomass burning aerosol over West Africa during DABEX, J. Geophys. Res., 113, D00C06, doi:10.1029/2007JD009451.

Junker, C., and C. Liousse (2008), A global emission inventory of carbonaceous aerosol from historic records of fossil fuel and biofuel consumption for the period 1860-1997, Atmos. Chem. Phys., 8(5), 1195-1207, doi:10.5194/acp-8-1195-2008.

Kahn, R. A., B. J. Gaitley, J. V. Martonchik, D. J. Diner, K. A. Crean, and B. Holben (2005), Multiangle Imaging Spectroradiometer (MISR) globa aerosol optical depth validation based on 2 years of coincident Aerosol Robotic Network (AERONET) observations, J. Geophys. Res., 110, D10S04, doi:10.1029/2004JD004706.

Kanamitsu, M., W. Ebisuzaki, J. Woolen, S. K. Yang, J. J. Hnilo, M. Fiorino, and J. Potter (2002), NCEP/DOE AMIP-II Reanalysis (R-2), Bull. Am. Meteorol. Soc., 83, 1631-1643, doi:10.1175/BAMS-83-11-1631(2002) $083<1631:$ NAR $>2.3 . \mathrm{CO} ; 2$

Kaufman, Y. J., D. Tanré, L. A. Remer, E. F. Vermote, A. Chu, and B. N. Holben (1997), Operational remote sensing of tropospheric aerosol over land from EOS moderate resolution imaging spectroradiometer, J. Geophys. Res., 102(D14), 17,051-17,067, doi:10.1029/96JD03988.

Kiehl, J. T., J. J. Hack, G. B. Bonan, B. A. Boville, B. P. Breigleb, D. Williamson, and P. Rasch (1996), Description of the NCAR Community Climate Model (CCM3), NCAR Tech. Rep. NCAR/TN-420+STR, NCAR, Boulder, Colo.

Kiehl, J., J. J. Hack, G. B. Bonan, B. A. Boville, D. L. Williamson, and P. J. Rasch (1998), The National Center for Atmospheric Research Community Climate Model: CCM3, J. Clim., 11(6), 1131-1149, doi:10.1175/1520-0442(1998)011<1131:TNCFAR>2.0.CO;2.

Kim, S., P. Chazette, F. Dulac, J. Sanak, B. Johnson, and S. Yoon (2009), Vertical structure of aerosols and water vapor over West Africa during the African monsoon dry season, Atmos. Chem. Phys., 9(20), 8017-8038, doi:10.5194/acp-9-8017-2009.

Kirchstetter, T. W., T. Novakov, and P. V. Hobbs (2004), Evidence that the spectral dependence of light absorption by aerosols is affected by organic carbon, J. Geophys. Res., 109, D21208, doi:10.1029/2004JD004999.

Klüser, L., and T. Holzer-Popp (2010), Mineral dust effects on clouds and rainfall in the West African Sahel, Atmos. Chem. Phys. Discuss., 10(3), 6167-6197, doi:10.5194/acpd-10-6167-2010.

Konaré, A., A. S. Zakey, F. Solmon, F. Giorgi, S. Rauscher, S. Ibrah, and X. Bi (2008), A regional climate modelling study of the effect of desert dust on the West African monsoon, J. Geophys. Res., 113, D12206, doi:10.1029/2007JD009322.

Lau, K. M., K. M. Kim, Y. C. Sud, and G. K. Walker (2009), A GCM study of the response of the atmospheric water cycle of West Africa and the Atlantic to Saharan dust radiative forcing, Ann. Geophys., 27(10), 4023-4037, doi:10.5194/angeo-27-4023-2009.

Laurent, B., B. Marticorena, G. Bergametti, J. F. Lon, and N. M. Mahowald (2008), Modeling mineral dust emissions from the Sahara desert using new surface properties and soil database, J. Geophys. Res., 113 , D14218, doi:10.1029/2007JD009484.

Lawrence, M. G., T. M. Butler, J. Steinkamp, B. R. Gurjar, and J. Lelieveld (2007), Regional pollution potentials of megacities and other major population centers, Atmos. Chem. Phys., 7(14), 3969-3987, doi:10. 5194/ acp-7-3969-2007.

Lemaître, C., C. Flamant, J. Cuesta, J. Raut, P. Chazette, P. Formenti, and J. Pelon (2010), Radiative forcing associated with a springtime case of Bodélé and Sudan dust transport over West Africa, Atmos. Chem. Phys. Discuss., 10(4), 8811-8858, doi:10.5194/acpd-10-8811-2010.

Léon, J., Y. Derimian, I. Chiapello, D. Tanré, T. Podvin, B. Chatenet, A. Diallo, and C. Deroo (2009), Aerosol vertical distribution and optical properties over M'Bour (16.96 w;14.39 n), Senegal from 2006 to 2008, Atmos. Chem. Phys., 9(23), 9249-9261, doi:10.5194/acp-9-9249-2009.

Levy, R. C., L. A. Remer, S. Mattoo, E. F. Vermote, and Y. J. Kaufman (2007), Second-generation operational algorithm: Retrieval of aerosol properties over land from inversion of moderate resolution imaging spectroradiometer spectral reflectance, J. Geophys. Res., 112, D13211, doi:10.1029/2006JD007811.

Liousse, C., J. E. Penner, C. Chuang, J. J. Walton, H. Eddleman, and H. Cachier (1996), A global three-dimensional model study of carbonaceous aerosols, J. Geophys. Res., 101(D14), 19,411-19,432, doi:10.1029/ 95JD03426.

Liousse, C., et al. (2004), Deriving global quantitative estimates for spatial and temporal distributions of biomass burning emissions, in Emissions of Atmospheric Trace Compounds, pp. 77-120, Kluwer Acad., Norwell, Mass.

Liousse, C., et al. (2010), Western African aerosols modelling with updated biomass burning emission inventories in the frame of the AMMA-IDAF program, Atmos. Chem. Phys. Discuss., 10(3), 7347-7382, doi:10.5194/ acpd-10-7347-2010.
Magi, B. I., and P. V. Hobbs (2003), Effects of humidity on aerosols in southern Africa during the biomass burning season, J. Geophys. Res., 108(D13), 8495, doi:10.1029/2002JD002144.

Mallet, M., et al. (2008), Aerosol direct radiative forcing over Djougou (northern Benin) during the African Monsoon Multidisciplinary Analysis dry season experiment (Special Observation Period-0), J. Geophys. Res., 113, D00C01, doi:10.1029/2007JD009419.

Mallet, M., P. Tulet, D. Sera, F. Solmon, O. Dubovik, J. Pelon, V. Pont, and O. Thouron (2009), Impact of dust aerosols on the radiative budget, surface heat fluxes, heating rate profiles and convective activity over West Africa during march 2006, Atmos. Chem. Phys., 9(18), 7143-7160, doi:10.5194/acp-9-7143-2009.

Markowicz, K. M., P. J. Flatau, A. M. Vogelmann, P. K. Quinn, and E. J. Welton (2003), Clear-sky infrared aerosol radiative forcing at the surface and the top of the atmosphere, Q. J. R. Meteorol. Soc., 129(594), 2927-2947, doi:10.1256/qj.02.224

Marticorena, B., and G. Bergametti (1995), Modeling the atmospheric dust cycle: 1. Design of a soil-derived dust emission scheme, J. Geophys. Res., 100(D8), 16,415-16,430, doi:10.1029/95JD00690.

McConnell, C. L., E. J. Highwood, H. Coe, P. Formenti, B. Anderson, S. Osborne, S. Nava, K. Desboeufs, G. Chen, and M. A. J. Harrison (2008), Seasonal variations of the physical and optical characteristics of Saharan dust: Results from the Dust Outflow and Deposition to the Ocean (DODO) experiment, J. Geophys. Res., 113, D14S05, doi:10.1029/2007JD009606.

McConnell, C. L., P. Formenti, E. J. Highwood, and M. A. J. Harrison (2010), Using aircraft measurements to determine the refractive index of Saharan dust during the DODO experiments, Atmos. Chem. Phys., 10(6), 3081-3098, doi:10.5194/acp-10-3081-2010.

McFarlane, S. A., E. I. Kassianov, J. Barnard, C. Flynn, and T. P. Ackerman (2009), Surface shortwave aerosol radiative forcing during the atmospheric radiation measurement mobile facility deployment in Niamey, Niger, J. Geophys. Res., 114, D00E06, doi:10.1029/2008JD010491.

Michel, C., C. Liousse, J. Grégoire, K. Tansey, G. R. Carmichael, and J. Woo (2005), Biomass burning emission inventory from burnt area data given by the SPOT-VEGETATION system in the frame of TRACE-P and ACE-Asia campaigns, J. Geophys. Res., 110, D09304, doi:10.1029/ 2004JD005461.

Miller, R. L., I. Tegen, and J. Perlwitz (2004), Surface radiative forcing by soil dust aerosols and the hydrologic cycle, J. Geophys. Res., 109, D04203, doi:10.1029/2003JD004085.

Milton, S. F., G. Greed, M. E. Brooks, J. Haywood, B. Johnson, R. P. Allan, A. Slingo, and W. M. F. Grey (2008), Modeled and observed atmospheric radiation balance during the West African dry season: Role of mineral dust, biomass burning aerosol, and surface albedo, J. Geophys. Res., 113, D00C02, doi:10.1029/2007JD009741.

Myhre, G., A. Grini, J. M. Haywood, F. Stordal, B. Chatenet, D. Tanré, J. K. Sundet, and I. S. A. Isaksen (2003), Modeling the radiative impact of mineral dust during the Saharan Dust Experiment (SHADE) campaign, J. Geophys. Res., 108(D18), 8579, doi:10.1029/2002JD002566.

Myhre, G., et al. (2004), Intercomparison of satellite retrieved aerosol optical depth over the ocean, J. Atmos. Sci., 61(5), 499-513, doi:10.1175/ 1520-0469(2004)061<0499:IOSRAO>2.0.CO;2.

Myhre, G., C. Hoyle, T. Berglen, B. Johnson, and J. Haywood (2008), Modeling of the solar radiative impact of biomass burning aerosols during the Dust and Biomass-burning Experiment (DABEX), J. Geophys. Res., 113, D00C16, doi:10.1029/2008JD009857.

Otto, S., M. de Reus, T. Trautmann, A. Thomas, M. Wendisch, and S. Borrmann (2007), Atmospheric radiative effects of an in situ measured Saharan dust plume and the role of large particles, Atmos. Chem. Phys. 7(18), 4887-4903, doi:10.5194/acp-7-4887-2007.

Pal, J., et al. (2007), Regional climate modeling for the developing worldThe ICTP RegCM3 and regCNET, Bull. Am. Meteorol. Soc., 88(9), 1395-1409, doi:10.1175/BAMS-88-9-1395.

Pelon, J., M. Mallet, A. Mariscal, P. Goloub, D. Tanré, D. B. Karam, C. Flamant, J. Haywood, B. Pospichal, and S. Victori (2008), Microlidar observations of biomass burning aerosol over Djougou (Benin) during African Monsoon Multidisciplinary Analysis Special Observation Period 0: Dust and Biomass-Burning Experiment, J. Geophys. Res., 113, D00C18, doi:10.1029/2008JD009976.

Perlwitz, J., and R. L. Miller (2010), Cloud cover increase with increasing aerosol absorptivity: A counterexample to the conventional semidirect aerosol effect, J. Geophys. Res., 115, D08203, doi:10.1029/ 2009JD012637.

Peyrillé, P., J.-P. Lafore, and J.-L. Redelsperger (2007), An idealized twodimensional framework to study the West African monsoon, part I: Validation and key controlling factors, J. Atmos. Sci., 64(8), 2765-2782, doi:10.1175/JAS3919.1. 
Pinker, R. T., H. Liu, S. R. Osborne, and C. Akoshile (2010), Radiative effects of aerosols in sub-Sahel Africa: Dust and biomass burning, J. Geophys. Res., 115, D15205, doi:10.1029/2009JD013335.

Pont, V., M. Mallet, C. Liousse, L. Gomes, F. Malavelle, F. Solmon, C. Galy, E. Gardrat, and P. Castéra (2009), Mixing of dust and carbonaceous aerosols: Three concepts of chemical scheme from AMMA dry season experiment (SOP 0 - January 2006) at Djougou (Benin), paper presented at AMMA Conference, AMMA, Ouagadougou, Burkina Faso. Prospero, J. M., P. Ginoux, O. Torres, S. E. Nicholson, and T. E. Gill (2002), Environmental characterization of global sources of atmospheric soil dust identified with the NIMBUS7 total ozone mapping spectrometer (TOMS) absorbing aerosol product, Rev. Geophys., 40(1), 1002, doi:10.1029/2000RG000095.

Qian, Y., F. Giorgi, Y. Huang, W. Chameides, and C. Luo (2001), Regional simulation of anthropogenic sulfur over east Asia and its sensitivity to model parameters, Tellus, Ser. B, 53(2), 171-191, doi:10.1034/j.16000889.2001.d01-14.x.

Raut, J., and P. Chazette (2008), Radiative budget in the presence of multilayered aerosol structures in the framework of AMMA SOP-0, Atmos. Chem. Phys., 8(22), 6839-6864, doi:10.5194/acp-8-6839-2008.

Reid, J. S., T. F. Eck, S. A. Christopher, R. Koppmann, O. Dubovik, D. P. Eleuterio, B. N. Holben, E. A. Reid, and J. Zhang (2005), A review of biomass burning emissions part III: Intensive optical properties of biomass burning particles, Atmos. Chem. Phys., 5(3), 827-849, doi:10.5194/acp5-827-2005.

Russell, P., et al. (2002), Comparison of aerosol single scattering albedos derived by diverse techniques in two North Atlantic experiments, J. Atmos. Sci., 59(3), 609-619, doi:10.1175/1520-0469(2002)059<0609: COASSA $>2.0 . \mathrm{CO} ; 2$.

Satheesh, S. K., and V. Ramanathan (2000), Large differences in tropical aerosol forcing at the top of the atmosphere and Earth's surface, Nature, 405(6782), 60-63, doi:10.1038/35011039.

Schkolnik, G., D. Chand, A. Hoffer, M. Andreae, C. Erlick, E. Swietlicki, and Y. Rudich (2007), Constraining the density and complex refractive index of elemental and organic carbon in biomass burning aerosol using optical and chemical measurements, Atmos. Environ., 41(5), 1107-1118, doi:10.1016/j.atmosenv.2006.09.035.

Slingo, A., et al. (2006), Observations of the impact of a major Saharan dust storm on the atmospheric radiation balance, Geophys. Res. Lett., 33, L24817, doi:10.1029/2006GL027869.

Slingo, A., H. E. White, N. A. Bharmal, and G. J. Robinson (2009), Overview of observations from the RADAGAST experiment in Niamey, Niger: 2. Radiative fluxes and divergences, J. Geophys. Res., 114, D00E04, doi:10.1029/2008JD010497.

Sokolik, I. N., and O. B. Toon (1999), Incorporation of mineralogical composition into models of the radiative properties of mineral aerosol from UV to IR wavelengths, J. Geophys. Res., 104(D8), 9423-9444, doi:10.1029/1998JD200048.

Solmon, F., F. Giorgi, and C. Liousse (2006), Aerosol modelling for regional climate studies: Application to anthropogenic particles and evaluation over a European/African domain, Tellus, Ser. B, 58(1), 51-72, doi:10.1111/j.1600-0889.2005.00155.x.

Solmon, F., M. Mallet, N. Elguindi, F. Giorgi, A. Zakey, and A. Konaré (2008), Dust aerosol impact on regional precipitation over western Africa mechanisms and sensitivity to absorption properties, Geophys. Res. Lett., 35, L24705, doi:10.1029/2008GL035900.

Stephens, G. L. (1984), The parameterization of radiation for numerical weather prediction and climate models, Mon. Weather Rev., 112, 826 , doi:10.1175/1520-0493(1984)112<0826:TPORFN>2.0.CO;2.
Sud, Y. C., E. Wilcox, W. K.-M. Lau, G. K. Walker, X.-H. Liu, A. Nenes, D. Lee, K.-M. Kim, Y. Zhou, and P. S. Bhattacharjee (2009), Sensitivity of boreal-summer circulation and precipitation to atmospheric aerosols in selected regions-part 1: Africa and India, Ann. Geophys., 27(10), 3989-4007, doi:10.5194/angeo-27-3989-2009.

Tanré, D., F. M. Bréon, J. L. Deuzé, M. Herman, P. Goloub, F. Nadal, and A. Marchand (2001), Global observation of anthropogenic aerosols from satellite, Geophys. Res. Lett., 28(24), 4555-4558, doi:10.1029/ 2001 GL013036.

Todd, M. C., et al. (2008), Quantifying uncertainty in estimates of mineral dust flux: An intercomparison of model performance over the Bodélé depression, northern Chad, J. Geophys. Res., 113, D24107, doi:10.1029/ 2008JD010476.

Tulet, P., M. Mallet, V. Pont, J. Pelon, and A. Boone (2008), The 7-13 March 2006 dust storm over West Africa: Generation, transport, and vertical stratification, J. Geophys. Res., 113, D00C08, doi:10.1029/ 2008JD009871.

Tummon, F., F. Solmon, C. Liousse, and M. Tadross (2010), Simulation of the direct and semi-direct aerosol effects on the southern Africa regional climate during the biomass burning season, J. Geophys. Res., 115 , D19206 doi:10.1029/2009JD013738.

United Nations (2005), World urbanization prospects: The 2005 revision, vol. I, Comprehensive tables, $E S A / P / W P / 2005$, Geneva, Switzerland. (Available at www.un.org/esa/population/publications/WUP2005/ 2005wup.htm)

van der Werf, G. R., J. T. Randerson, G. J. Collatz, L. Giglio, P. S. Kasibhatla, A. F. Arellano Jr., S. C. Olsen, and E. S. Kasischke (2004), Continentalscale partitioning of fire emissions during the 1997 to $2001 \mathrm{El} \mathrm{Niño/}$ La Niña period, Science, 303(5654), 73-76, doi:10.1126/science.1090753.

van der Werf, G. R., J. T. Randerson, L. Giglio, G. J. Collatz, P. S. Kasibhatla, and A. F. Arellano Jr. (2006), Interannual variability in global biomass burning emissions from 1997 to 2004, Atmos. Chem. Phys., 6(11), 3423-3441, doi:10.5194/acp-6-3423-2006

Wang, H., G. Shi, S. Li, W. Li, B. Wang, and Y. Huang (2006), The impacts of optical properties on radiative forcing due to dust aerosol, Adv. Atmos. Sci., 23, 431-441, doi:10.1007/s00376-006-0431-5.

Yoshioka, M., N. M. Mahowald, A. J. Conley, W. D. Collins, D. W. Fillmore, C. S. Zender, and D. B. Coleman (2007), Impact of desert dust radiative forcing on Sahel precipitation: Relative importance of dust compared to sea surface temperature variations, vegetation changes, and greenhouse gas warming, J. Clim., 20(8), 1445-1467, doi:10.1175/ JCLI4056.1.

Zakey, A. S., F. Solmon, and F. Giorgi (2006), Implementation and testing of a desert dust module in a regional climate model, Atmos. Chem. Phys., 6(12), 4687-4704, doi:10.5194/acp-6-4687-2006.

Zarzycki, C. M., and T. C. Bond (2010), How much can the vertical distribution of black carbon affect its global direct radiative forcing?, Geophys. Res. Lett., 37, L20807, doi:10.1029/2010GL044555.

B. Johnson, Met Office, FitzRoy Road, Exeter, EX1 3PB, UK. (ben. johnson@metoffice.gov.uk)

J.-F. Leon, C. Liousse, F. Malavelle, M. Mallet, and V. Pont, Laboratoire d'Aérologie, UMR5560, Université Paul Sabatier, CNRS, 14 avenue Edouard Belin, F-31400 Toulouse, France. (malf@aero.obs-mip.fr)

F. Solmon, International Centre for Theoretical Physics, 11 Strada Costiera, I-34151 Trieste, Italy. (fsolmon@ictp.it) 